\title{
The Compound of Mangiferin-Berberine Salt Has Potent Activities in Modulating Lipid and Glucose Metabolisms in HepG2 Cells
}

\author{
Can Wang, ${ }^{1}$ Jian-Dong Jiang, ${ }^{2}$ Wei Wu, ${ }^{3}$ and Wei-Jia Kong ${ }^{1}$ \\ ${ }^{1}$ Department of Virology, Institute of Medicinal Biotechnology, Chinese Academy of Medical Sciences and \\ Peking Union Medical College, Beijing 100050, China \\ ${ }^{2}$ State Key Laboratory of Bioactive Natural Products and Function, Institute of Materia Medica, Chinese Academy of \\ Medical Sciences and Peking Union Medical College, Beijing 100050, China \\ ${ }^{3}$ Changzhou Deze Medical Science Co., Ltd., Changzhou, Jiangsu 213100, China
}

Correspondence should be addressed to Wei Wu; weiwubrenda@126.com and Wei-Jia Kong; wjkong894@163.com

Received 10 December 2015; Revised 28 February 2016; Accepted 7 March 2016

Academic Editor: Adair Santos

Copyright (C) 2016 Can Wang et al. This is an open access article distributed under the Creative Commons Attribution License, which permits unrestricted use, distribution, and reproduction in any medium, provided the original work is properly cited.

The mangiferin-berberine (MB) salt was synthesized by ionic bonding of mangiferin (M) and berberine (B) at an equal molecular ratio. This study aimed to investigate the activities of $\mathrm{MB}$ salt in modulating lipid and glucose metabolisms in HepG2 cells. After $24 \mathrm{~h}$ treatment of the studying compounds, cellular AMP-activated protein kinase $\alpha$ (AMPK $\alpha$ )/acetyl-CoA carboxylase (ACC) protein levels and carnitine palmitoyltransferase (CPT) 1 activities, intracellular lipid contents, mRNA expression levels of target genes, glucose consumption, and glucose production amounts were determined. Compound C (CC) was used in the blocking experiments. Our results showed that MB salt increased p-AMPK $\alpha$ (Thr172)/p-ACC (Ser79) levels and CPT1 activity and suppressed oleic acid- (OA-) induced lipid accumulation and upregulation of lipogenic genes potently in HepG2 cells. The above activities of $\mathrm{MB}$ salt were AMPK dependent and were superior to those of $\mathrm{M}$ or $\mathrm{B}$ when administered at an equal molar concentration. MB salt enhanced basal and insulin-stimulated glucose consumption and suppressed gluconeogenesis more potently than $\mathrm{M}$ or B alone. The inhibiting activity of MB salt on cellular gluconeogenesis was AMPK dependent. Our results may support MB salt as a new kind of agent for the development of novel lipid or glucose-lowering drugs in the future.

\section{Introduction}

The metabolism syndrome (MS) is characterized by dyslipidemia, glucose intolerance and/or insulin resistance, hypertension, and obesity [1]. If there are no proper interventions, MS may lead to diabetes and complications, coronary heart disease, or even cancer eventually. Currently, chemical drugs such as biguanide and thiazolidinedione are commonly used in clinic for treatment of MS in order to improve metabolic disorders [1].

In addition to the abovementioned chemical drugs, numerous studies indicated that natural products isolated from plants might have beneficial effects in modulating lipid and glucose metabolisms, both in vitro and in animal models [2]. Some natural products are now subjected to clinical studies for the treatment of metabolic diseases; among them, a few compounds may have promising application prospects [3].

Mangiferin (M, Figure 1(a)), a xanthone glycoside, is a natural compound extracted from plants such as Mangifera indica and Anemarrhena asphodeloides. It was reported to have hypolipidemic [4-7], hypoglycemic [8-12], insulinsensitizing [13], antiobesity [8,9], antioxidative [14-16], and anti-inflammatory $[14,17]$ activities in animal models as well as in clinic. The beneficial effects of $\mathrm{M}$ on lipid and glucose metabolisms might be related to the activation of AMPactivated protein kinase (AMPK) $[5,17,18]$, a key molecule that controls energy balance and metabolism in organisms [19].

Berberine (B, Figure 1(a)), an isoquinoline alkaloid, is a natural compound isolated from plants such as Coptis 
<smiles>O=c1c2cc(O)c(O)cc2oc2cc(O)c(C3OC(CO)[C@H](O)[C@H](O)[C@H]3O)c(O)c12</smiles>

M, MW: 422.3

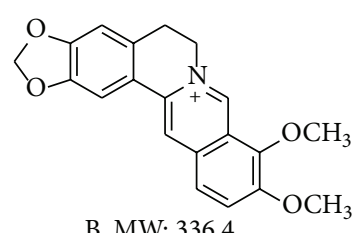

B, MW: 336.4

MB salt, MW: 758.7

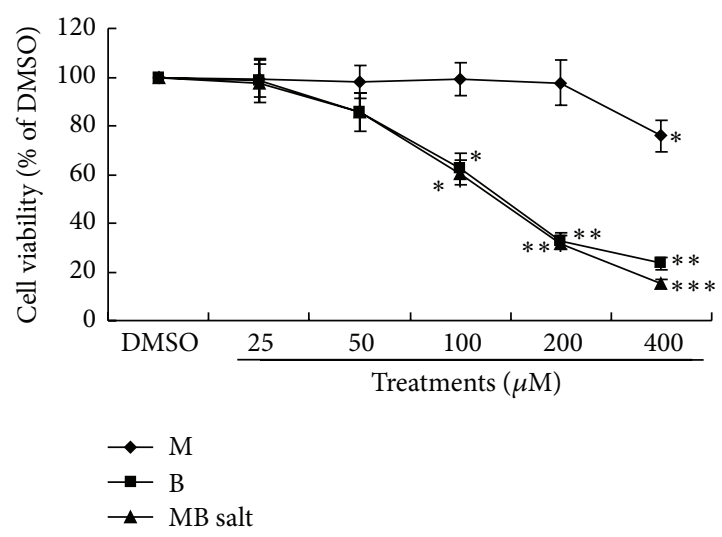

(b)

(a)

FIGURE 1: Influence of MB salt/M/B on cell viability. (a) Chemical structure and molecular weight (MW) of MB salt. (b) HepG2 cells were treated with the studying compounds at different concentrations for $24 \mathrm{~h}$. Cell viability was determined by MTT staining and presented as percentages of control cells, which were treated with DMSO (0.5\%) and defined as 100 . Values are mean \pm SD of 3 separate experiments; ${ }^{*} p<0.05,{ }^{* *} p<0.01$, and ${ }^{* * *} p<0.001$ versus that of DMSO.

chinensis. B has a variety of pharmacological activities, and numerous studies demonstrated that it was a promising agent in modulating lipid and glucose metabolisms [3,20,21]. Now, $B$ is undergoing clinical studies to systematically evaluate its efficacy and safety. The molecular mechanisms of B in modulating lipid and glucose metabolisms, which may include low-density lipoprotein receptor (LDLR) upregulation [22], AMPK activation [21], and gut microbiota modulation [23], are not fully elucidated and still need further investigation.

The compound of mangiferin-berberine (MB, Figure 1(a)) salt was synthesized by chemical bonding of $\mathrm{M}$ and $\mathrm{B}$ at an equal molecular ratio [24]. The nuclear magnetic resonance (NMR) data demonstrated that, in $\mathrm{MB}$ salt, $\mathrm{M}$ group (acidic) and $\mathrm{B}$ group (alkaline) conjugated by ionic bond to form a stable single molecule [24]. Due to the well-defined roles of $\mathrm{M}$ and $\mathrm{B}$ in improving metabolic disorders, it can be expected that this new compound may have favourable activities in modulating metabolism. Indeed, in pilot studies, the MB salt was found to stimulate the AMPK pathway in L6 skeletal muscle cells, lower blood glucose and lipids, and improve insulin sensitivity and liver function in KK-Ay diabetic mice [24]. However, the detailed activities and mechanisms of this new compound are still undefined. In the present report, we study the efficacies of MB salt in HepG2 cells and find that it has potent activities in stimulating AMPK and modulating lipid/glucose metabolisms, which are superior to those of $\mathrm{M}$ or $\mathrm{B}$ alone.

\section{Materials and Methods}

2.1. Chemicals and Reagents. The MB salt was synthesized by Changzhou Deze Medical Science Co., Ltd., as described previously [24]. M and B were supplied by the Northeast Pharmaceutical Group Shenyang No. 1 Pharmaceutical Co., Ltd. (Shenyang, China). Methylthiotetrazole (MTT), dimethyl sulphoxide (DMSO), compound C (CC), sodium L-lactate, oleic acid (OA), and bovine serum albumin (BSA) were purchased from Sigma-Aldrich Co. (St. Louis, MO, USA). Fetal bovine serum (FBS), Dulbecco's modified Eagle's medium (DMEM), glucose-, pyruvate-, and phenol red-free DMEM, sodium pyruvate, and Amplex Red Glucose/Glucose Oxidase Assay Kit were purchased from Gibco-Invitrogen (Grand Island, NY, USA). Reagents required for protein extraction and quantification were obtained from Thermo Fisher Scientific Inc. (Waltham, MA, USA) [25]. Monoclonal antibodies specific for AMPK $\alpha$, phosphorylated AMPK $\alpha$ (pAMPK $\alpha$ ) (Thr172), acetyl-CoA carboxylase (ACC), phosphorylated ACC (p-ACC) (Ser79), and $\beta$-actin (ACTB) were obtained from Cell Signaling Technology, Inc. (Danvers, MA, USA). Immobilon ${ }^{\circledR}-\mathrm{P}$ polyvinylidene difluoride (PVDF) membranes were from EMD Millipore Corporation (Billerica, MA, USA). Cell carnitine palmitoyltransferase (CPT) 1 Activity Assay Kit was from GenMed Scientifics Inc. (Shanghai, China). Steatosis Colorimetric Assay Kit was purchased from Cayman Chemical (Ann Arbor, MI, USA). Cell Triglyceride (TG) Assay Kit was from the Applygen Technologies Inc. (Beijing, China). Reagents required for RNA isolation, reverse transcription, and real-time PCR were purchased from Promega (Madison, WI, USA) [25]. Glucose Assay Kit (based on glucose oxidase method) was from Beijing Strong Biotechnologies, Inc. (Beijing, China). Human insulin (Humulin ${ }^{\circledR}$ ) was purchased from Eli Lilly and Company (Shanghai, China).

2.2. Cell Culture. HepG2 cells were routinely cultured in DMEM plus $10 \%$ FBS and appropriate antibiotics in an atmosphere of $5 \% \mathrm{CO}_{2}$ at $37^{\circ} \mathrm{C}$. Before experiments, cells were trypsinized and allowed to grow to about $70-80 \%$ confluence. The cells were starved in $0.5 \%$ FBS-containing medium overnight before treatment.

2.3. Cell Viability Assay. HepG2 cells were seeded onto 96well plates with $2 \times 10^{4}$ cells per well. The studying compounds were dissolved with DMSO to make stock solutions 
at a concentration of $80 \mathrm{mM}$, which were stored at $-20^{\circ} \mathrm{C}$ in aliquots. Before usage, the stock solutions were thawed and serially diluted with DMEM $+0.5 \%$ FBS. After $24 \mathrm{~h}$ of incubation and serum starvation, cells were treated with the studying compounds for $24 \mathrm{~h}$ as indicated (Figure 1(b)); each treatment had 5 replicate wells. Control cells were treated with $0.5 \%$ DMSO in DMEM + 0.5\% FBS, a concentration with no cytotoxicity [26] and equal to the concentration of DMSO in cells treated with $400 \mu \mathrm{M}$ of studying compounds. Cell viability was determined by MTT staining as described previously [27]; the absorbance was read by a VICTOR ${ }^{\mathrm{TM}} \mathrm{X} 4$ Multilabel Plate Reader (PerkinElmer, Inc., Waltham, MA, USA) at a wavelength of $595 \mathrm{~nm}$. The results were presented as percentages of control cells, which were defined as 100 . The values of $50 \%$ inhibiting concentrations ( $\mathrm{IC}_{50}$ values) of the compounds were calculated as described before [27].

2.4. Western Blot. After treatment with the studying compounds for $24 \mathrm{~h}$, cell total proteins were extracted and quantified. Samples containing about $20 \mu \mathrm{g}$ of protein were used for $10 \%$ sodium dodecyl sulfate polyacrylamide gel electrophoresis (SDS-PAGE). The blots were then transferred from gels onto PVDF membranes as described previously [25]. After blocking, the protein levels of AMPK $\alpha$, ACC, and ACTB were detected with specific monoclonal antibodies and an appropriate secondary antibody; signals were developed with an ECL kit (EMD Millipore Corporation). p-AMPK $\alpha$ (Thr172) and p-ACC (Ser79) levels were examined by phosphospecific antibodies after removal of antibody binding from the membranes. After scanning and quantification, the levels of p-AMPK $\alpha$ (Thr172) and p-ACC (Ser79) were normalized to those of AMPK $\alpha$ and ACC and plotted as indicated.

2.5. Cellular CPT1 Activity Assay. After treatment for $24 \mathrm{~h}$, cells were harvested; samples containing $50 \mu \mathrm{g}$ of protein were used for CPT1 activity assay according to the supplier's protocol. The CPT1 experiments were repeated for 3 times; cellular CPT1 activities were presented as nmol of coenzyme $\mathrm{A}(\mathrm{CoA})$ produced in the assay system per minute.

2.6. Induction of Steatosis, Oil Red O (ORO) Staining, and Intracellular TG Assay. OA was dissolved in sterile phosphate buffered saline (PBS) + 5\% BSA [28] to make a stock solution of $6 \mathrm{mM}$ and was stored at $-20^{\circ} \mathrm{C}$ in aliquots. Before usage, the stock solution was thawed and diluted with DMEM + $0.5 \%$ FBS for 10 times. HepG2 cells were seeded onto 6-well plates with $5 \times 10^{5}$ cells per well. After $24 \mathrm{~h}$ of incubation and serum starvation, cells were left untreated or treated with $0.6 \mathrm{mM}$ of $\mathrm{OA}$ for $24 \mathrm{~h}$. MB salt/M/B were serially diluted from their stock solutions with DMEM + 0.5\% FBS; at the same time of OA administration, they were added to the cells at indicated concentrations, except for some cells which were used as OA control. After treatment, intracellular lipids were stained with ORO by the Steatosis Colorimetric Assay Kit according to the supplier's protocol. After staining, the cells were observed under a light microscope and photographed. In parallel experiments, cells were harvested after treatment;
TABle 1: Primers for real-time PCR $\left(5^{\prime}\right.$ to $\left.3^{\prime}\right)$.

\begin{tabular}{lll}
\hline Gene & Forward primer & Reverse primer \\
\hline LDLR & aggacggctacagctaccc & ctccaggcagatgttcacg \\
PEPCK & gctctgaggaggagaatgg & tgctcttgggtgacgataac \\
G6Pase & gtgaattaccaagactcccag & gcccatggcatggccagaggg \\
SREBP1c & cgacatcgaagacatgcttcag & ggaaggcttcaagagaggagc \\
ChREBP & agagacaagatccgcctgaa & cttccagtagttccctcca \\
FAS & gacatcgtccattcgtttgtg & cggatcaccttcttgagctcc \\
SCD1 & ggtgatgttccagaggaggta & ggcagagtagtcataggaaagg \\
GAPDH & agccacatcgctcagacac & gcccaatacgaccaaatcc \\
\hline
\end{tabular}

intracellular TG contents were determined by the Cell TG Assay Kit and normalized to protein concentrations; mRNA levels of lipogenic transcription factors and their target genes (Table 1) were determined by real-time reverse transcriptasepolymerase chain reaction (RT-PCR).

2.7. RNA Extraction and Real-Time RT-PCR. Total RNA was isolated from cells and reversely transcribed into cDNAs according to the supplier's protocols. We performed real-time PCR in an ABI Prism ${ }^{\circledR} 7900$ High-Throughput Real-Time PCR System (Applied Biosystems, Foster City, CA, USA) with gene specific primers (Table 1 ). The reaction condition was the same as our previous report [25]. For relative quantification of target genes, the comparative threshold cycle $\left(\mathrm{C}_{\mathrm{T}}\right)$ method was used with glyceraldehyde-3-phosphate dehydrogenase (GAPDH) as an internal control. The mRNA expression levels of target genes were plotted as fold of control cells, which were designated as 1 .

2.8. Glucose Consumption Assay. HepG2 cells were seeded onto 24 -well plates with $2 \times 10^{5}$ cells per well. For basal glucose consumption assay, cells were treated with DMSO or the studying compounds for $24 \mathrm{~h}$ as indicated, with 4 replicate wells for each treatment. For insulin-stimulated glucose consumption assay, cells were treated with $0.05 \mathrm{nM}$ of human insulin (diluted with DMEM + 0.5\% FBS) together with DMSO or the studying compounds for $24 \mathrm{~h}$. Glucose levels in the supernatant of media were assayed with a commercially available kit. Glucose consumption was calculated as glucose level of the fresh medium minus glucose level of the cultured medium.

2.9. Glucose Production Assay. Cells were seeded and treated as in the glucose consumption assay. After treatment with the studying compounds, cells were washed twice with PBS. The glucose production medium was prepared by adding sodium pyruvate and sodium L-lactate to the glucose-, pyruvate-, and phenol red-free DMEM to final concentrations of $2 \mathrm{mM}$ and $20 \mathrm{mM}$, respectively. For one well of the 24 -well plate, cells were loaded with $100 \mu \mathrm{L}$ of the glucose production medium and incubated for $4 \mathrm{~h}$ at $37^{\circ} \mathrm{C}$. Glucose concentrations in the supernatant were analyzed by the Amplex Red Glucose/Glucose Oxidase Assay Kit according to the supplier's protocol. The values were normalized to protein 
concentrations and presented as percentages of DMSO control, which was defined as 100. In parallel experiments, cells were harvested for real-time RT-PCR analysis of the key genes involved in gluconeogenesis after $24 \mathrm{~h}$ treatment of studying compounds.

2.10. Blocking Experiments. After serum starvation, cells were pretreated with $10 \mu \mathrm{M}$ of CC (dissolved in DMSO) for $30 \mathrm{~min}$; then studying compounds or OA were added. $24 \mathrm{~h}$ later, cells were harvested for western blot, CPT1 activity assay, oil red $\mathrm{O}(\mathrm{ORO})$ staining, intracellular TG assay, basal glucose consumption assay, glucose production assay, or real-time RT-PCR.

2.11. Statistical Analysis. Values are mean \pm SD of 3-4 repeated experiments. After validation of the test for homogeneity of variance, differences among studying groups were examined by one-way ANOVA followed by the NewmanKeuls test for multiple comparisons. $p<0.05$ was considered to be statistically significant.

\section{Results}

3.1. Cytotoxicities of Studying Compounds. First, we determined the influences of $\mathrm{MB}$ salt/M/B on cell viability by the MTT method. As shown in Figure 1(b), after $24 \mathrm{~h}$ treatment, $\mathrm{M}$ alone reduced the viability of HepG2 cells only when its concentration reached $400 \mu \mathrm{M}(p<0.05$ versus DMSO). The $\mathrm{IC}_{50}$ of $\mathrm{M}$ is larger than $400 \mu \mathrm{M}$. For B and MB salt, cell viabilities declined slightly with no statistical significance when their concentrations reached $50 \mu \mathrm{M}$, which was in agreement with a previous report [29]. When the concentrations of B and $\mathrm{MB}$ salt reached $100 \mu \mathrm{M}$, cell viabilities declined significantly as compared to that of DMSO $(p<0.05)$. And when their concentrations reached $400 \mu \mathrm{M}$, there were only averagely $23.4 \%$ and $15.3 \%$ living cells left after $24 \mathrm{~h}$ treatment $(p<0.01$ or $p<0.001$ versus DMSO). The $\mathrm{IC}_{50}$ values of $\mathrm{B}$ and $\mathrm{MB}$ salt were $133.9 \pm 10.6 \mu \mathrm{M}$ and $131.0 \pm 9.4 \mu \mathrm{M}$, respectively. Our result was close to a previous report, in which the $\mathrm{IC}_{50}$ value of $\mathrm{B}$ was $42.33 \mu \mathrm{g} / \mathrm{mL}$ in HepG2 cells [30]. We observed that the cells remained in good and healthy state if the concentrations of $\mathrm{B}$ and $\mathrm{MB}$ salt did not exceed $50 \mu \mathrm{M}$. So, the maximum concentrations of the studying compounds we used in the following experiments were $50 \mu \mathrm{M}$.

3.2. $M B$ Salt Activates AMPK More Potently Than $M$ or $B$ Alone. As shown in Figure 2(a), MB salt increased the levels of p-AMPK $\alpha$ (Thr172) and p-ACC (Ser79) in dose-dependent manners after $24 \mathrm{~h}$ of administration. $\mathrm{MB}$ salt at $12.5 \mu \mathrm{M}$ could stimulate the cellular AMPK pathway significantly $(p<$ 0.05 versus $\mathrm{DMSO}$ ). The stimulating activities of $\mathrm{MB}$ salt on the phosphorylation of AMPK and ACC were completely blocked by CC (Figure 2(b)), a specific inhibitor of AMPK. To compare the bioactivities of $\mathrm{MB}$ salt/M/B in stimulating AMPK, we used these compounds to treat HepG2 cells at an equal molar concentration. As shown in Figure 2(c), when administered alone, $25 \mu \mathrm{M}$ of $\mathrm{M}$ and $\mathrm{B}$ could increase $\mathrm{p}$ AMPK $\alpha$ (Thr172) and p-ACC (Ser79) levels by about 78\%$85 \%(p<0.05$ versus DMSO). For comparison, MB salt at $25 \mu \mathrm{M}$ increased p-AMPK $\alpha$ (Thr172) and p-ACC (Ser79) levels averagely by 1.61- and 1.67-fold, respectively $(p<0.01$ versus DMSO). The efficacy of MB salt on the AMPK/ACC pathway was significantly superior to that of $\mathrm{M}$ or $\mathrm{B}$ alone $(p<0.05)$.

We then determined the influences of the studying compounds on cellular CPT1 activity. As shown in Figure 3(a), in HepG2 cells, MB salt enhanced CPT1 activity in a manner similar to that of AMPK, which could be abolished by CC pretreatment (Figure 3(b)). And again, the activity of $\mathrm{MB}$ salt on CPT1 was stronger than that of $\mathrm{M}$ or $\mathrm{B}$ when treated alone $(p<0.05)$ (Figure 3(c)). Taken together, the above results demonstrate that MB salt is a potent AMPK activator and its bioactivity is superior to that of $\mathrm{M}$ or $\mathrm{B}$ alone.

3.3. MB Salt Suppresses Hepatic Steatosis More Effectively Than $M$ or $B$ Alone. To investigate the influence of MB salt on lipid metabolism, HepG2 cells were challenged with OA [31]. As shown in Figure 4, $0.6 \mathrm{mM}$ of OA treatment for $24 \mathrm{~h}$ induced steatosis and increased intracellular TG level ( $p<0.001$ versus untreated) dramatically in HepG2 cells, as determined by ORO staining and intracellular TG assay. Coadministration of $\mathrm{MB}$ salt prevented steatosis and reduced intracellular TG content in dose-dependent manners (data not shown). The efficacies of MB salt were completely blocked by CC pretreatment (Figure 4(a)). The MB salt suppressed hepatic steatosis and TG accumulation more effectively than $\mathrm{M}$ or $\mathrm{B}$ when administered at an equal molar concentration. As shown in Figure 4(b), $25 \mu \mathrm{M}$ of MB salt treatment for $24 \mathrm{~h}$ reduced intracellular TG content averagely by $56.9 \%(p<$ 0.01 versus $\mathrm{OA}$ alone), which was superior to that of $\mathrm{M}$ or B alone $(p<0.05)$.

In parallel with the development of steatosis, the mRNA expression levels of lipogenic transcription factors like sterol regulatory element-binding protein 1c (SREBP1c) and carbohydrate responsive element-binding protein (ChREBP) as well as their target genes like fatty acid synthase (FAS) and stearoyl-CoA desaturase 1 (SCD1) increased greatly after OA administration (Figure 5, $p<0.001$ versus untreated). The $\mathrm{MB}$ salt suppressed the upregulation of the above genes in dose-dependent (Figure 5(a)) and AMPK-dependent (Figure 5(b)) manners. In agreement with its stimulating activity on AMPK and inhibiting activity on steatosis, the MB salt reduced the expression levels of lipogenic genes more effectively than $\mathrm{M}$ or $\mathrm{B}$ alone $(p<0.05$, Figure $5(\mathrm{c}))$. Taken together, these results indicate that MB salt suppresses lipogenesis, steatosis, and TG accumulation in HpeG2 cells through AMPK activation, and its efficacies are more potent than $\mathrm{M}$ or $\mathrm{B}$ alone.

As $B$ is able to upregulate LDLR mRNA expression in liver cells [22], we want to know whether or not $M$ has the same activity. As shown in Figure 6(a), M alone had no influence on hepatic LDLR expression even when its concentration reached $100 \mu \mathrm{M}$. On the contrary, LDLR mRNA level could be upregulated by B at $12.5 \mu \mathrm{M}$ in HepG2 cells $(p<0.05$ versus DMSO) (Figure 6(b)). The activity of MB salt on LDLR expression was the same as that of B alone (Figure 6(b)). 

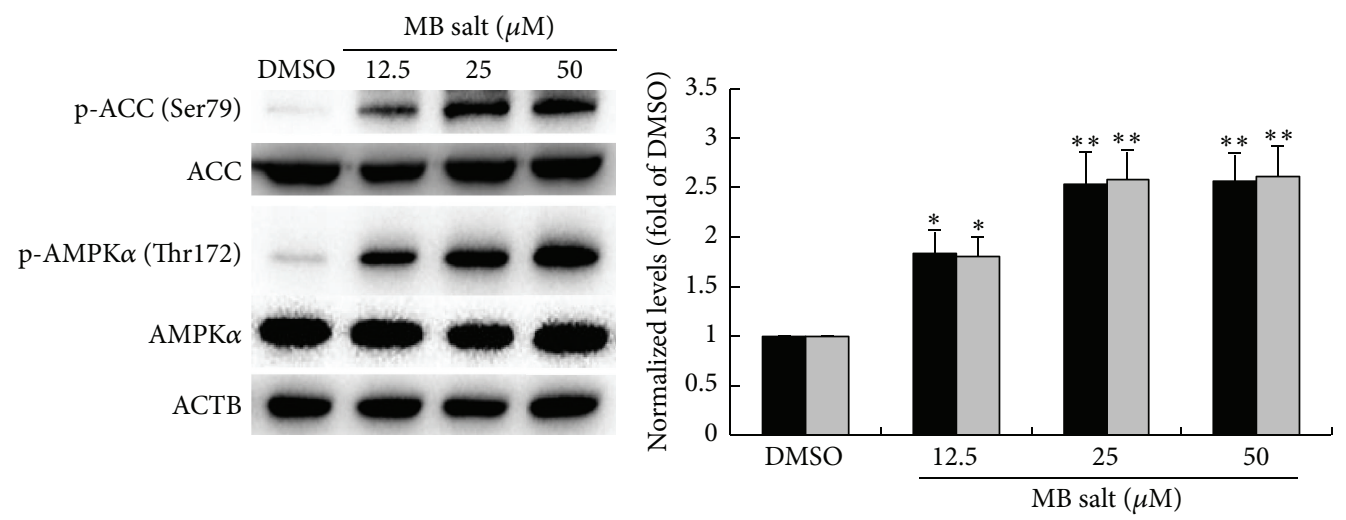

$$
\begin{aligned}
& \square \text { p-AMPK } \alpha \\
& \square \text { p-ACC }
\end{aligned}
$$

(a)
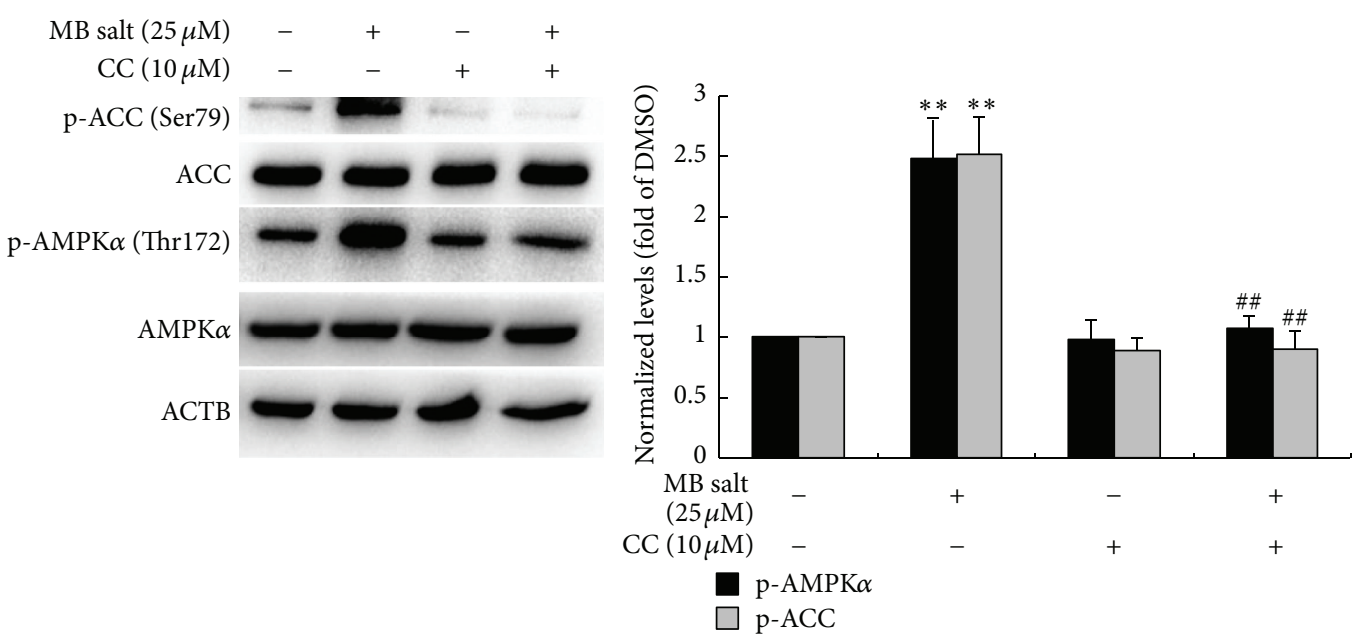

(b)
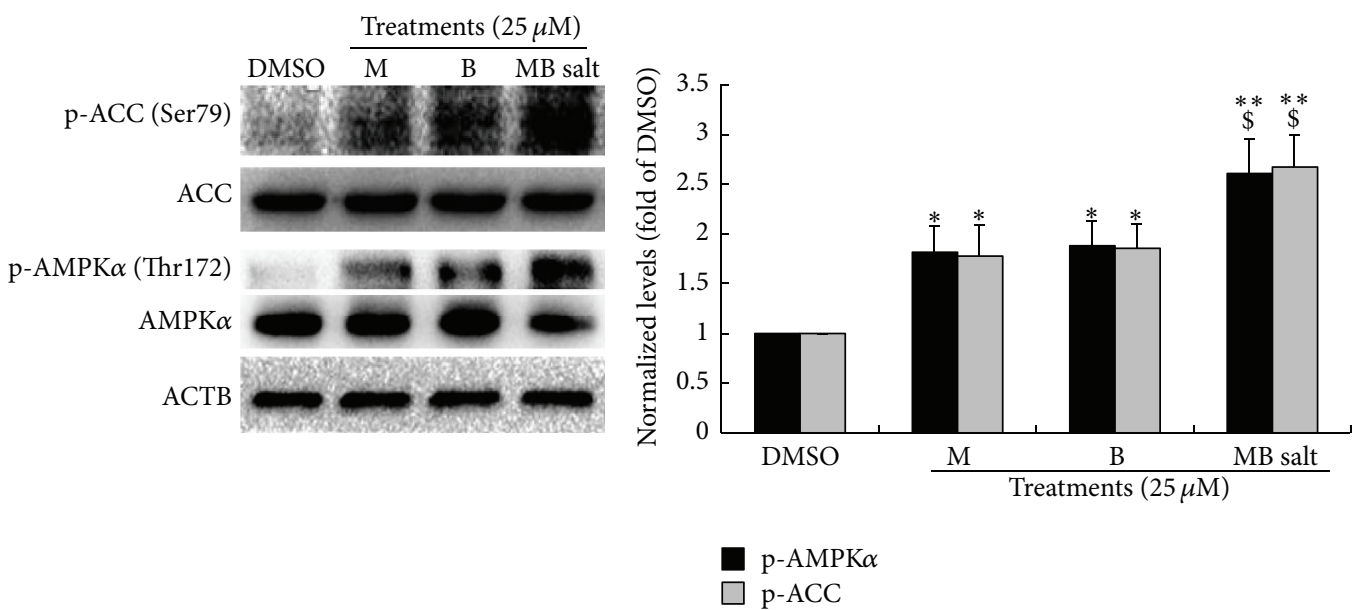

(c)

FIGURE 2: Stimulating effect of MB salt on the AMPK pathway. After serum starvation, cells were treated with different concentrations of MB salt for $24 \mathrm{~h}$ (a). Alternatively, cells were pretreated with CC for $30 \mathrm{~min}$; then MB salt was added and incubated for $24 \mathrm{~h}$ (b). In the comparison experiment, an equal concentration of MB salt/M/B was used to treat the cells for $24 \mathrm{~h}$ (c). DMSO (0.1\%) was used as control. After treatment, cell total proteins were extracted; the levels of p-AMPK $\alpha$ (Thr172), AMPK $\alpha$, p-ACC (Ser79), ACC, and ACTB were determined by western blot. Representative blots are presented. The protein levels of p-AMPK $\alpha$ (Thr172) and p-ACC (Ser79) were normalized to those of AMPK $\alpha$ and ACC, respectively, and plotted as fold of DMSO treated cells. Values are mean \pm SD of 3 separate experiments; ${ }^{*} p<0.05$ and ${ }^{* *} p<0.01$ versus that of DMSO; ${ }^{\# \#} p<0.01$ versus that of MB salt alone in (b); ${ }^{\$} p<0.05$ versus those of $\mathrm{M}$ alone or $\mathrm{B}$ alone in (c). 


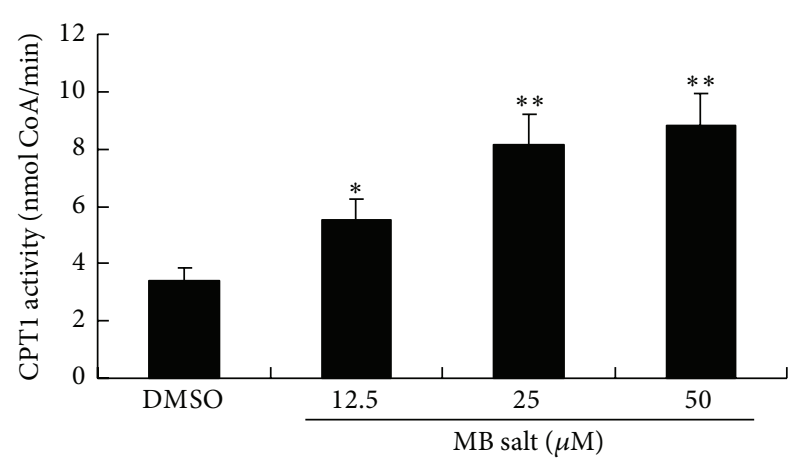

(a)

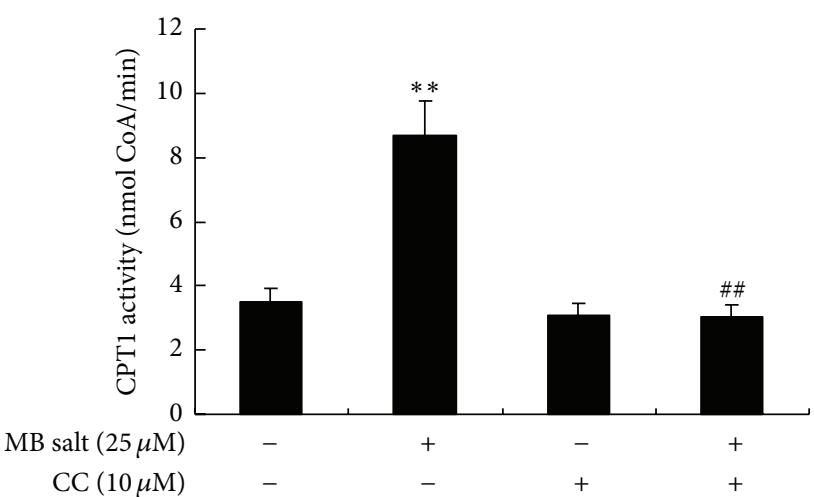

(b)

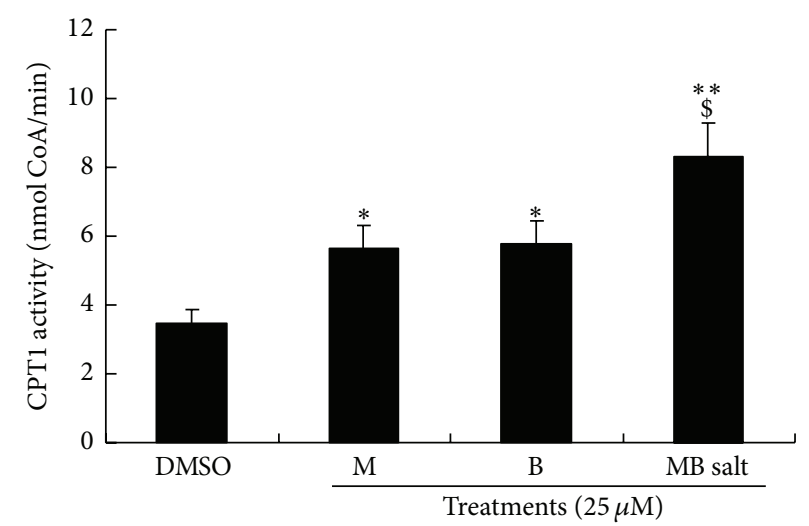

(c)

FIGURE 3: Stimulating effect of MB salt on CPT1 activity. HepG2 cells were treated the same as Figure 2. Cellular CPT1 activities were determined by a commercially available kit using equal amounts of proteins. Values are mean \pm SD of 3 separate experiments; ${ }^{*} p<0.05$ and ${ }^{* *} p<0.01$ versus that of DMSO; ${ }^{\# *} p<0.01$ versus that of MB salt alone in (b); ${ }^{\$} p<0.05$ versus that of $\mathrm{M}$ alone or B alone in (c).

3.4. MB Salt Stimulates Glucose Consumption and Suppresses Gluconeogenesis More Potently Than M or B Alone. Next, we investigated the activities of the studying compounds on glucose metabolism. As shown in Figure 7(a), MB salt stimulated basal glucose consumption in HepG2 cells in a dose-dependent manner. The efficacy of MB salt was superior to that of $\mathrm{M}$ or $\mathrm{B}(p<0.05)$ when administered at an equal molar concentration (Figure $7(\mathrm{~b})$ ). Furthermore, our result showed that the basal glucose consumptionstimulating activity of B was not influenced by CC (data not shown), which was in agreement with a previous report [29]. On the contrary, pretreatment of CC totally abolished the stimulating activity of $\mathrm{M}$ on cellular basal glucose consumption (Figure 7(c)), indicating that the activity of $M$ was AMPK dependent. Interestingly, when MB salt was used to treat the cells together with CC, its activity on basal glucose consumption was partially inhibited. As shown in Figure $7(d)$, cellular basal glucose consumption in the presence of $\mathrm{MB}$ salt $+\mathrm{CC}$ was significantly less than that of MB salt alone $(p<0.05)$, but still higher than DMSO treated cells $(p<0.05)$. This result was consistent with the blocking experiments using $\mathrm{M}$ (Figure $7(\mathrm{c})$ ) or B (data not shown) alone.
The above results indicated that MB salt itself could stimulate glucose metabolism without insulin. Previous studies by us and other researchers showed that $M$ and $B$ could stimulate insulin sensitivity $[13,20]$. So, we also determined the influences of these compounds on insulin-stimulated glucose consumption in HpG2 cells. As shown in Figures 7(a) and 7(b), $0.05 \mathrm{nM}$ of human insulin treatment for $24 \mathrm{~h}$ caused a slight increase of glucose consumption with no statistical significance. The MB salt enhanced insulin-stimulated glucose consumption dose-dependently (Figure 7(a)) and more potently than $\mathrm{M}$ or B alone $(p<0.05$, Figure $7(\mathrm{~b}))$. Notably, when $\mathrm{MB}$ salt/M/B were coadministered with $0.05 \mathrm{nM}$ of insulin, additional glucose consumptions could be obtained as compared to those of basal glucose consumptions $(p<$ 0.05 , Figures $7(\mathrm{a})$ and $7(\mathrm{~b}))$. Taken together, these results suggest that $\mathrm{MB}$ salt has potent activity in stimulating both basal and insulin-stimulated glucose consumptions in HpeG2 cells and its activities are superior to those of $\mathrm{M}$ or $\mathrm{B}$.

AMPK activation was proved to inhibit gluconeogenesis [19], so we also determined the influences of these compounds on gluconeogenesis. As shown in Figure 8(a), $\mathrm{MB}$ salt inhibited glucose production dose-dependently in HepG2 cells. Accordingly, the expression levels of 

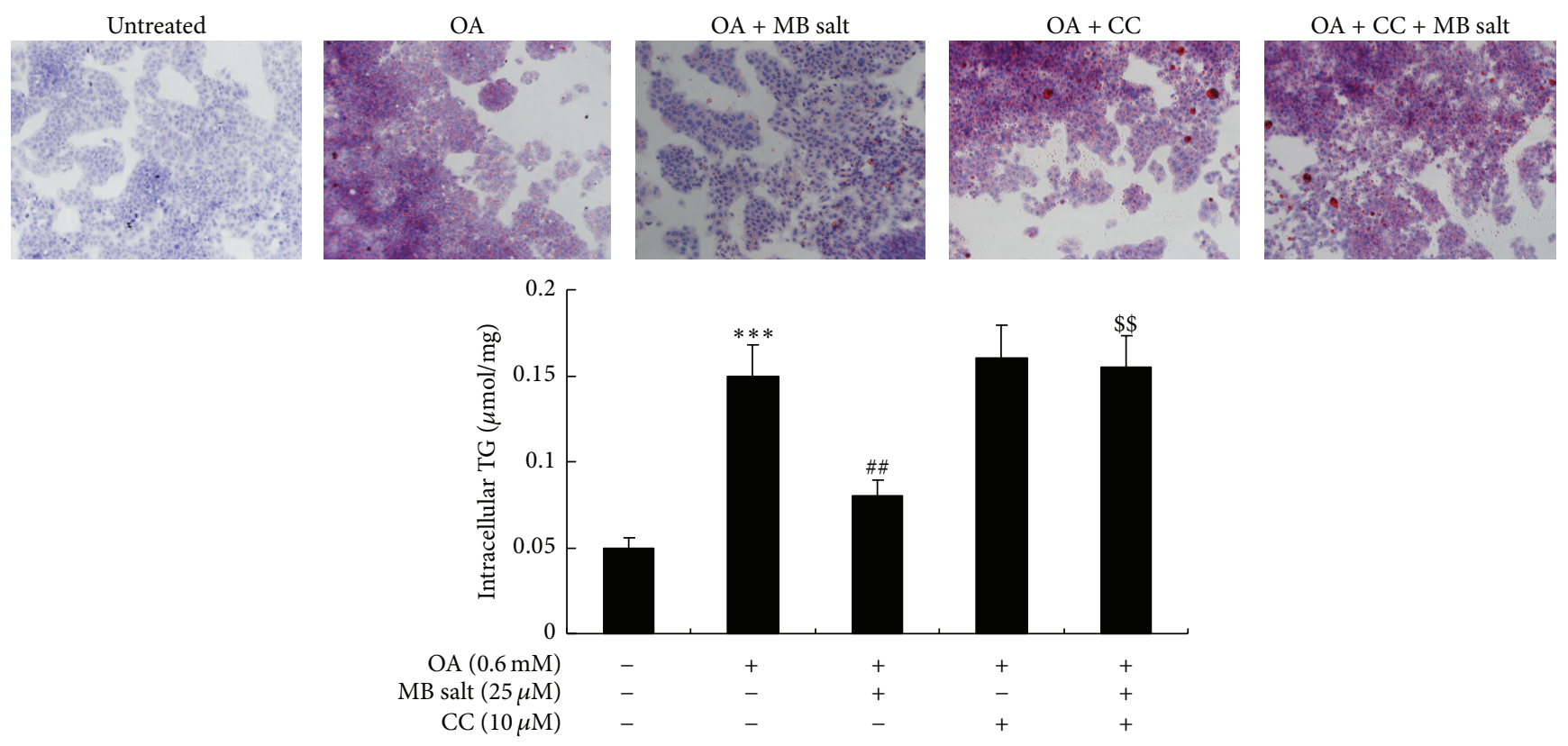

(a)
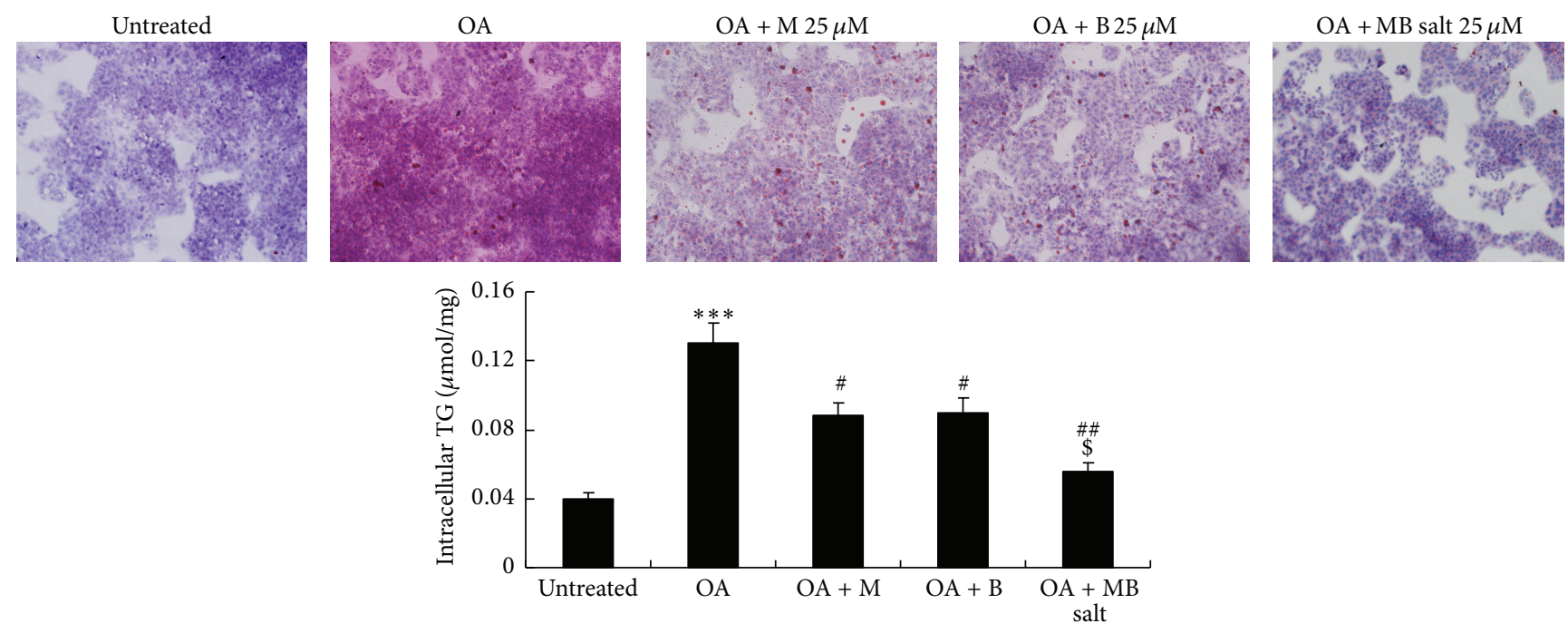

(b)

FIGURE 4: Effects of MB salt on OA-induced steatosis and TG accumulation. (a) HepG2 cells were left untreated or pretreated with CC for $30 \mathrm{~min}$; then the cells were again left untreated or treated with OA or OA + MB salt as indicated. $24 \mathrm{~h}$ later, cells were used for ORO staining (upper panel) or harvested for intracellular TG assay (lower panel). Representative pictures are presented. Values are mean \pm SD of 4 separate experiments; ${ }^{* * *} p<0.001$ versus that of untreated cells; ${ }^{\# \#} p<0.01$ versus that of OA alone; ${ }^{\$ \$} p<0.01$ versus that of OA $+\mathrm{MB}$ salt. (b) Cells were left untreated or treated with OA and an equal concentration of MB salt/M/B as indicated for $24 \mathrm{~h}$. Then, cells were used for ORO staining (upper panel) or intracellular TG assay (lower panel). Representative pictures are presented. Values are mean \pm SD of 4 separate experiments; ${ }^{* * *} p<0.001$ versus that of untreated cells; ${ }^{\#} p<0.05$ and ${ }^{\# \#} p<0.01$ versus that of $\mathrm{OA}$ alone; ${ }^{\$} p<0.05$ versus that of $\mathrm{OA}+\mathrm{M}$ or $\mathrm{OA}+\mathrm{B}$.

phosphoenolpyruvate carboxykinase (PEPCK)/glucose-6phosphatase (G6Pase), two key enzymes of the gluconeogenesis pathway, were greatly downregulated by MB salt (Figure 9(a)). When administered at an equal molar concentration, MB salt had stronger activities in inhibiting glucose production (Figure 8(b)) and downregulating PEPCK/G6Pase (Figure $9(\mathrm{~b}))$ than $\mathrm{M}$ or B alone $(p<0.05)$. Furthermore, unlike glucose consumption, the suppressing activities of $\mathrm{MB}$ salt/M/B on glucose production (Figures $8(\mathrm{c}), 8(\mathrm{~d})$, and $8(\mathrm{e})$ ) and PEPCK/G6Pase expression (Figure 9(c) and data not shown) were totally abolished by CC. These results prove that MB salt suppresses gluconeogenesis in HepG2 cells through AMPK activation, and its efficacies are more potent than M or B alone. 


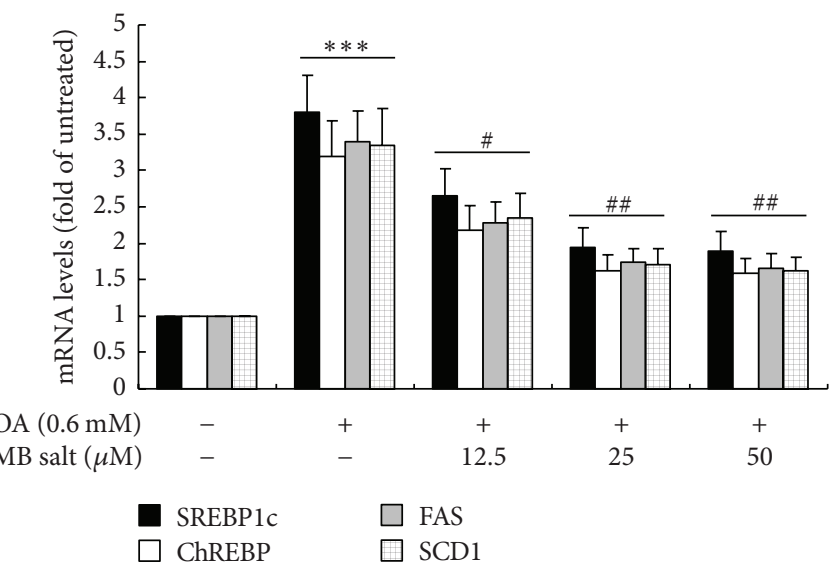

(a)

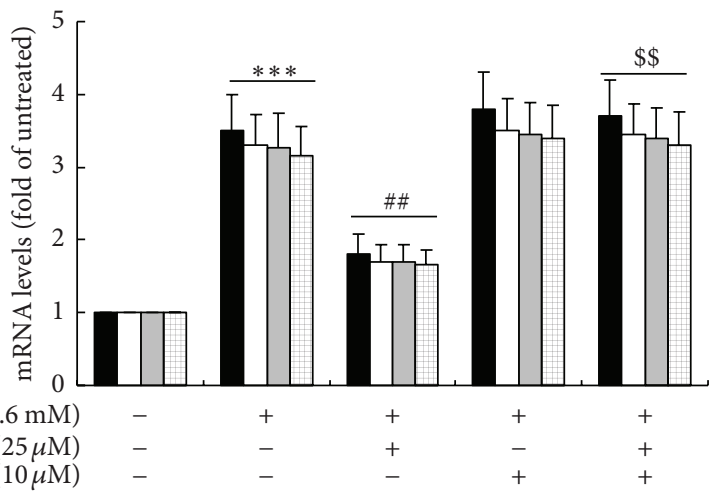

SREBP1C $\square$ FAS $\square$ ChREBP

(b)

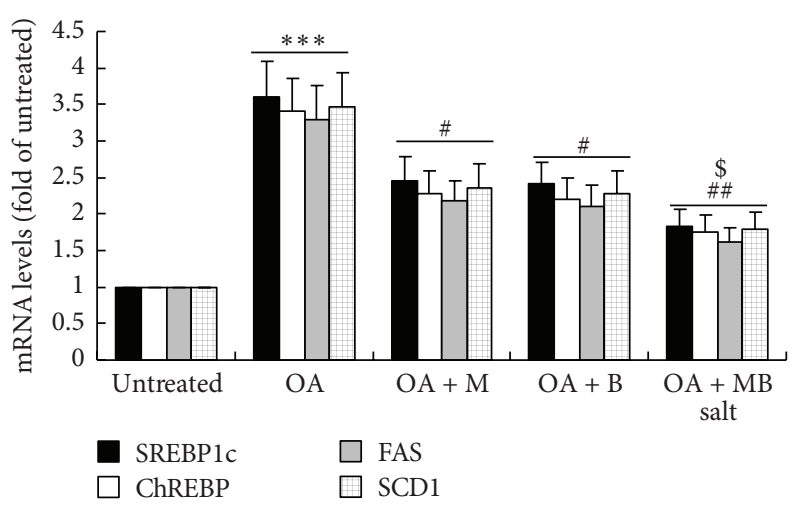

(c)

FIGURE 5: Effects of MB salt on the expression levels of lipogenic transcription factors and their target genes. (a) HepG2 cells were left untreated or treated with $\mathrm{OA}$ or $\mathrm{OA}+\mathrm{MB}$ salt as indicated. ${ }^{* * *} p<0.001$ versus that of untreated cells; ${ }^{\#} p<0.05$ and ${ }^{\# \#} p<0.01$ versus that of OA alone. (b) Cells were treated as described in Figure $4(\mathrm{a}) .{ }^{* * *} p<0.001$ versus that of untreated cells; ${ }^{\# \#} p<0.01$ versus that of OA alone; ${ }^{\$ \$} p<0.01$ versus that of $\mathrm{OA}+\mathrm{MB}$ salt. (c) Cells were treated as described in Figure 4(b). ${ }^{* * *} p<0.001$ versus that of untreated cells; ${ }^{\#} p<0.05$ and $\# p<0.01$ versus that of $\mathrm{OA}$ alone; ${ }^{\$} p<0.05$ versus that of $\mathrm{OA}+\mathrm{M}$ or $\mathrm{OA}+\mathrm{B}$. After treatment for $24 \mathrm{~h}$, cell total RNA was extracted for real-time RT-PCR determination of mRNA levels of indicated genes, which were normalized to that of GAPDH and plotted as fold of untreated cells. Values are mean \pm SD of 3 separate experiments.

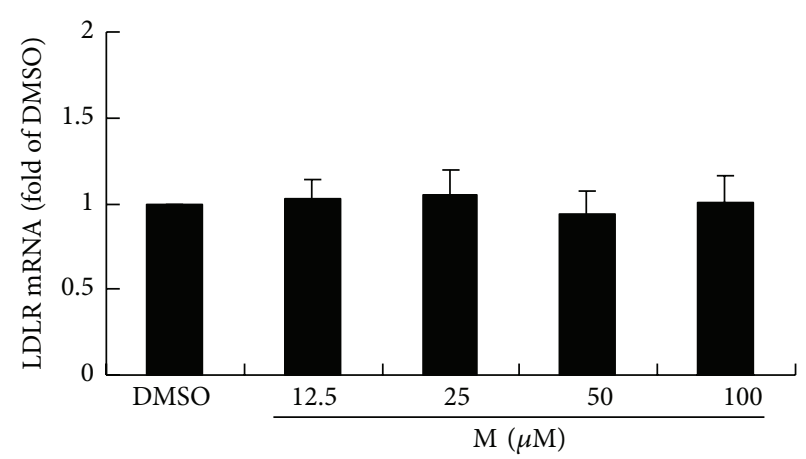

(a)

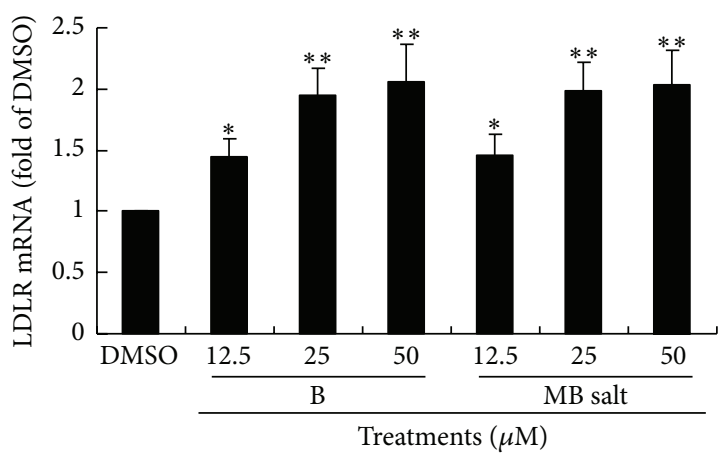

(b)

FIGURE 6: Effects of MB salt/M/B on LDLR mRNA levels. HepG2 cells were treated with different concentrations of M (a), B, or MB salt (b) for $24 \mathrm{~h}$. DMSO (0.1\%) was used as control. Cell total RNA was extracted for real-time RT-PCR determination of LDLR mRNA levels, which were normalized to that of GAPDH and plotted as fold of DMSO. Values are mean \pm SD of 3 separate experiments; ${ }^{*} p<0.05$ and ${ }^{* *} p<0.01$ versus that of DMSO. 


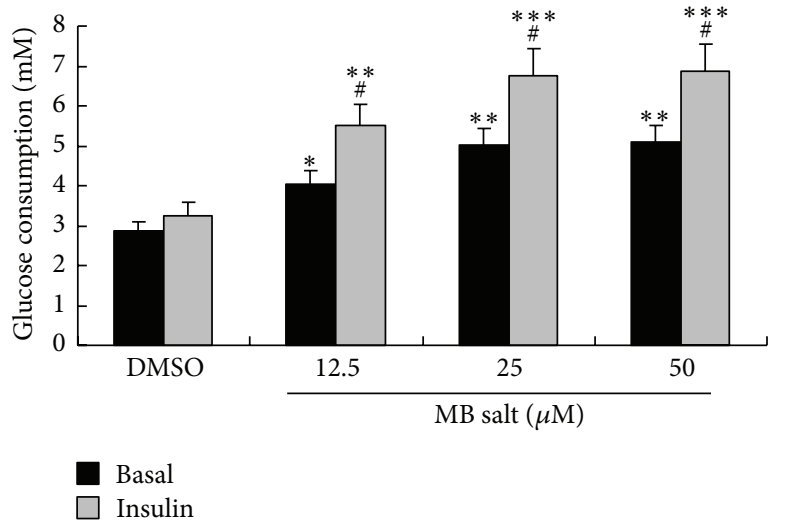

(a)

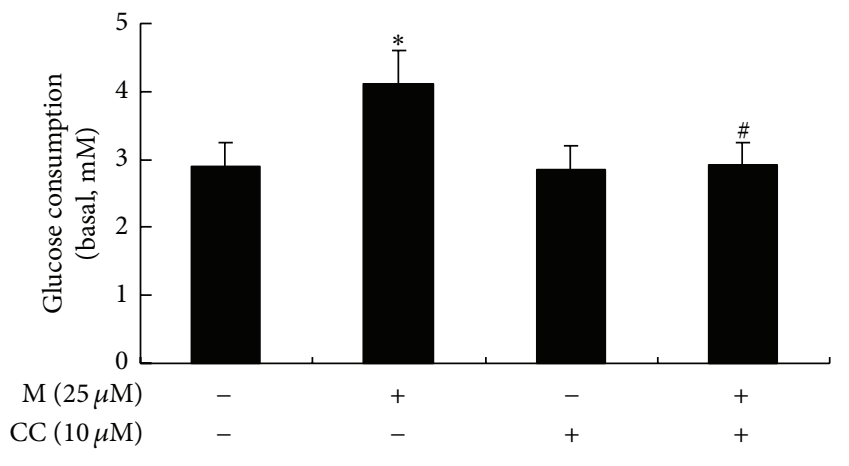

(c)

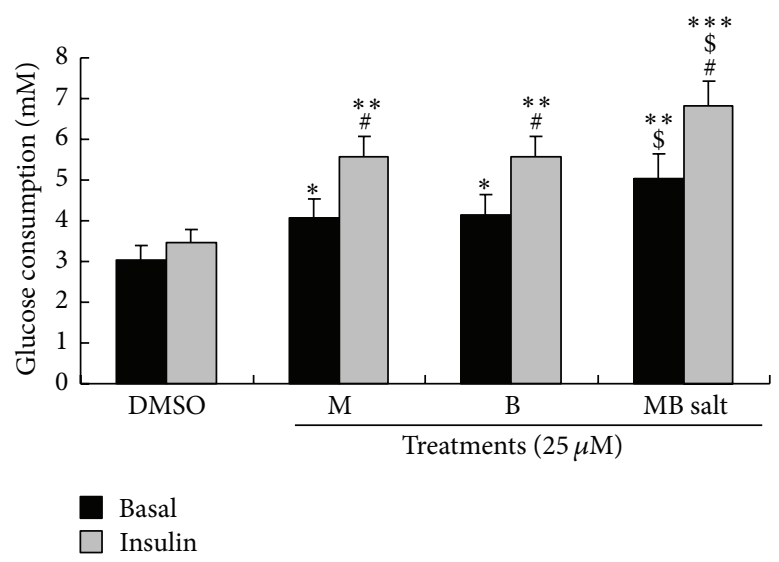

(b)

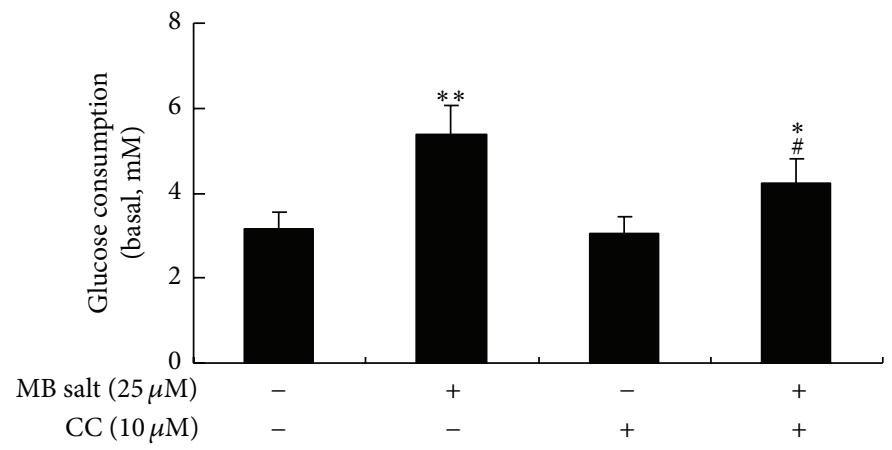

(d)

Figure 7: Effects of MB salt/M/B on basal and insulin-stimulated glucose consumptions. (a) After serum starvation, cells were treated with DMSO (0.1\%) or different concentrations of MB salt with or without $0.05 \mathrm{nM}$ of human insulin for $24 \mathrm{~h}$. Glucose levels in the culture media were assayed and glucose consumptions were calculated as described in Section 2. Values are mean \pm SD of 3 separate experiments; ${ }^{*} p<0.05$, ${ }^{* *} p<0.01$, and ${ }^{* * *} p<0.001$ versus that of DMSO; ${ }^{*} p<0.05$ versus that of basal glucose consumption. (b) HepG2 cells were treated with DMSO (0.1\%) or an equal concentration of MB salt/M/B with or without $0.05 \mathrm{nM}$ of human insulin for $24 \mathrm{~h}$; glucose consumptions were then calculated. Values are mean $\pm \mathrm{SD}$ of 3 separate experiments; ${ }^{*} p<0.05,{ }^{* *} p<0.01$, and ${ }^{* * *} p<0.001$ versus that of DMSO; ${ }^{*} p<0.05$ versus that of basal glucose consumption; ${ }^{\$} p<0.05$ versus that of $\mathrm{M}$ alone or B alone. (c and d) Cells were pretreated with CC for 30 min; then $\mathrm{M}$ (c) or MB salt (d) was added and incubated for $24 \mathrm{~h}$. DMSO $(0.1 \%)$ was used as control. After treatment, basal glucose consumptions were calculated. Values are mean \pm SD of 3 separate experiments; ${ }^{*} p<0.05$ and ${ }^{* *} p<0.01$ versus that of DMSO; ${ }^{*} p<0.05$ versus that of M alone (c) or MB salt alone (d).

\section{Discussion}

Here we report for the first time that $\mathrm{MB}$ salt, a novel compound synthesized by conjugation of natural products $M$ and $\mathrm{B}$, is a potent $\mathrm{AMPK}$ activator and has strong activities in modulating lipid and glucose metabolisms in HepG2 cells. As a single molecule, the advantages of $\mathrm{M}$ and $\mathrm{B}$ are able to be combined in $\mathrm{MB}$ salt, which has greater effectiveness in modulating lipid and glucose metabolisms as compared to either agent alone.

The activities and possible cellular pathways of $\mathrm{MB}$ salt in modulating lipid and glucose metabolisms are summarized in Figure 10. Our results revealed that MB salt could activate the AMPK pathway to a great extent in HepG2 cells at basal state. In another study, we proved that when treated with OA, the level of $\mathrm{p}$-AMPK $\alpha$ (Thr172) was downregulated in liver cells [32], which was in accordance with the increase of intracellular TG (Figure 4) and the upregulation of lipogenic genes (Figure 5). Our results suggested that the $\mathrm{MB}$ salt should also stimulate the AMPK pathway in OA-treated HepG2 cells, as blocking AMPK with CC totally abolished its suppressing efficacies on intracellular TG accumulation and lipogenic gene upregulation induced by OA.

As AMPK activators, $M$ and $B$ might act through different mechanisms. It was reported that B could inhibit mitochondrial respiratory chain complex I in liver cells and skeletal muscle cells, which resulted in the reduction of ATP biosynthesis and subsequent increase of AMP/ATP ratio $[29,33]$. Currently, it is generally accepted that B stimulates AMPK by increasing the cellular AMP/ATP ratio [29, 33, 34].

On the other hand, how AMPK was activated by M was not fully elucidated yet. One report suggested that $M$ could also increase AMP/ATP ratio [5]. According to that report [5], M might stimulate cellular AMPK through a mechanism similar to that of B. However, another study demonstrated that $\mathrm{M}$ in fact enhanced oxygen consumption and ATP 


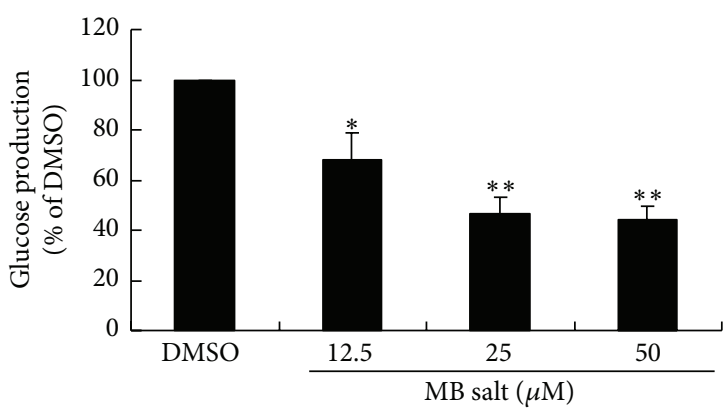

(a)

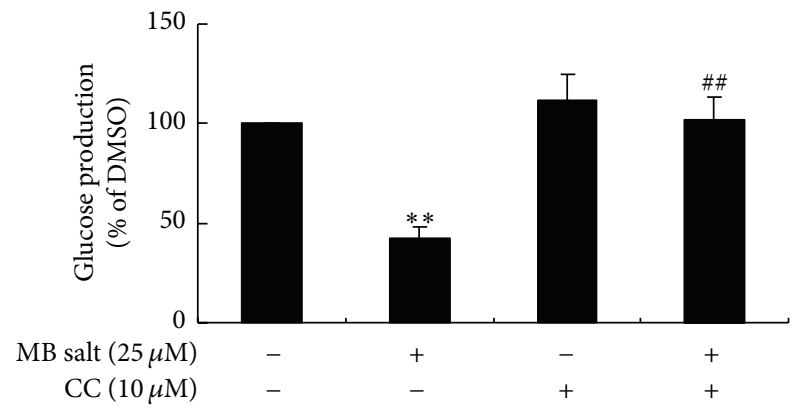

(c)

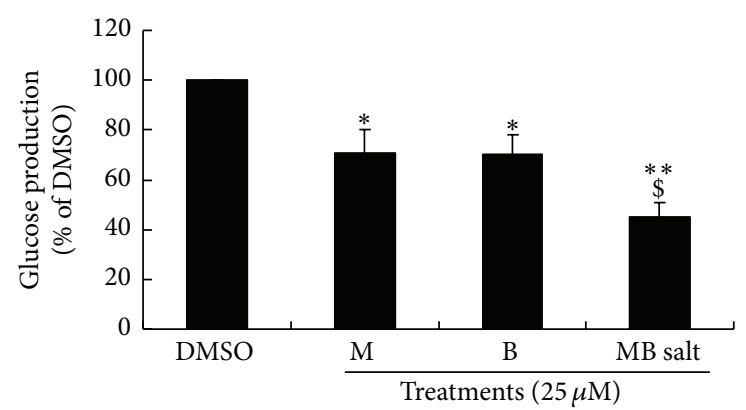

(b)

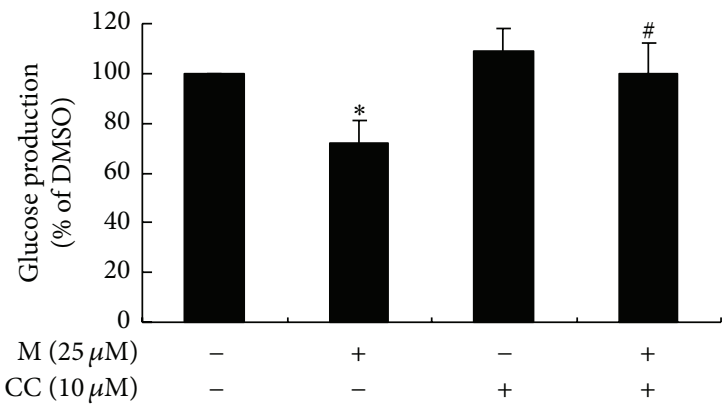

(d)

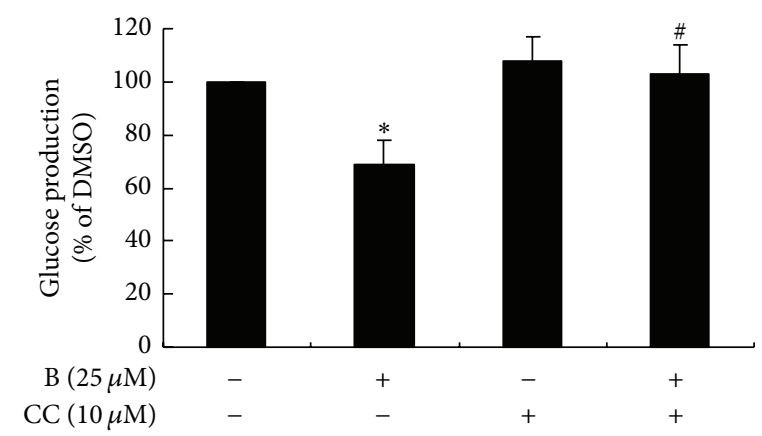

(e)

FIGURE 8: Effects of MB salt/M/B on glucose production. HepG2 cells were treated with different concentrations of MB salt (a) or an equal concentration of MB salt/M/B (b) for $24 \mathrm{~h}$. Alternatively, cells were pretreated with CC for 30 min; then MB salt (c), M (d), or B (e) was added and incubated for $24 \mathrm{~h}$. DMSO (0.1\%) was used as control. After treatment, culture media were discarded; cells were loaded with the glucose production medium as described in Section 2. Four hours later, glucose levels in the supernatant were determined, normalized to protein concentrations, and presented as percentages of DMSO. Values are mean \pm SD of 3 separate experiments; ${ }^{*} p<0.05$ and ${ }^{* *} p<0.01$ versus that of DMSO; ${ }^{\$} p<0.05$ versus that of $\mathrm{M}$ alone or B alone in (b); ${ }^{\#} p<0.05$ and ${ }^{\# \#} p<0.01$ versus that of MB salt alone (c), M alone (d), or B alone (e).

production but suppressed anaerobic respiration in muscle cells [9]. Interestingly, a recent study also showed that $\mathrm{M}$ had no influence on ATP amounts in 3T3-L1 preadipocytes [8]. In that study [8], the stimulating effect of M on AMPK was independent of liver kinase B1 (LKB1) but could be partially blocked by an inhibitor of calcium/calmodulin-dependent protein kinase kinase $\beta(\mathrm{CaMKK} \beta)$, an upstream kinase of AMPK. These findings suggest that the detailed mechanisms used by $\mathrm{M}$ to stimulate AMPK, which may involve CaMKK $\beta$, still need further investigation.

Although $\mathrm{M}$ and $\mathrm{B}$ might stimulate AMPK through different pathways, their activities were seemingly additive in the compound of MB salt (Figure 2(c)). AMPK is able to phosphorylate and suppress the catalytic activity of ACC [19]. The catalysate of ACC, malonyl-CoA, is an inhibitor of CPT1. AMPK activation will stimulate CPT1, which lead to the enhancement of fatty acid $\beta$-oxidation in the mitochondria [19]. Our results proved that MB salt stimulated CPT1 activity more effectively than $\mathrm{M}$ or $\mathrm{B}$ alone, which was in agreement with the cellular AMPK activity. As a result, OA-induced steatosis and TG accumulation in HepG2 cells were prevented by $\mathrm{MB}$ salt greatly, which might be due to the enhancement of fat burning. On the other hand, AMPK activation could inhibit lipogenesis by downregulating key lipogenic genes, as 


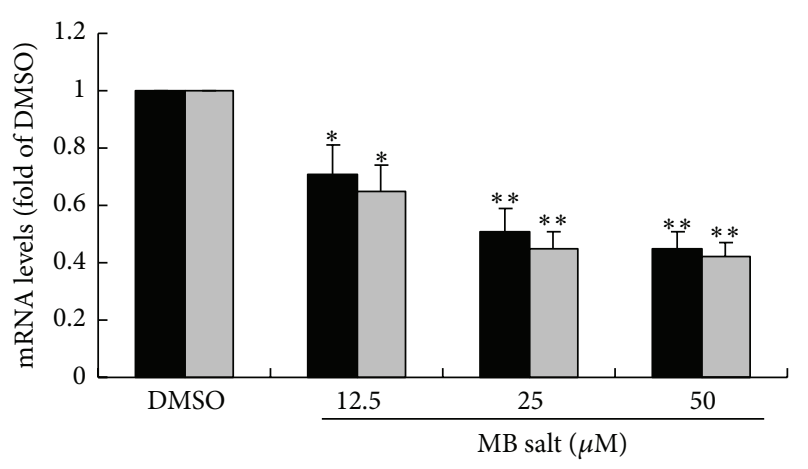

PEPCK G6Pase

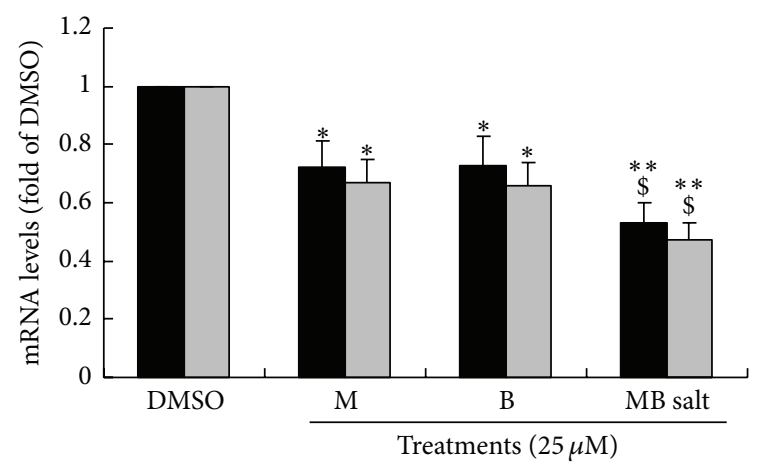

PEPCK

G6Pase (a)

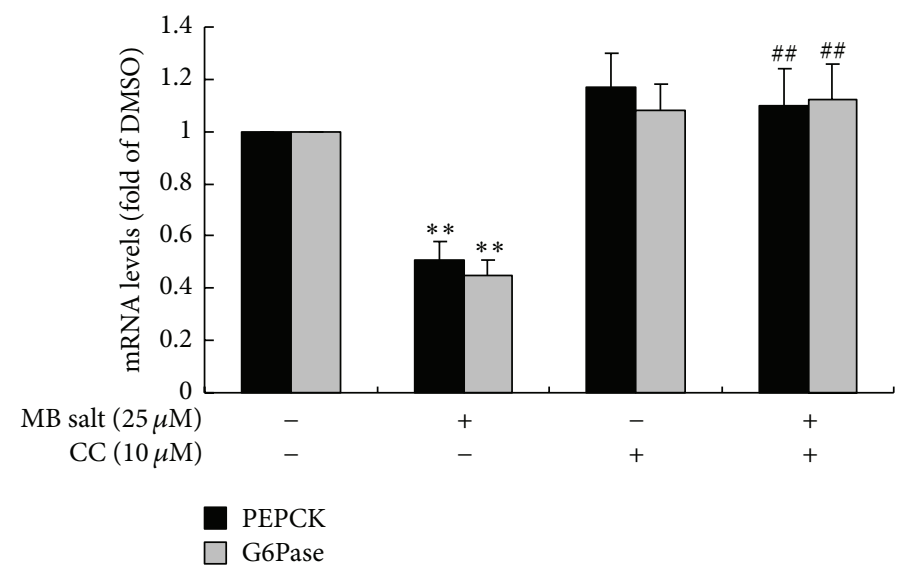

(b)

(c)

Figure 9: Effects of MB salt/M/B on PEPCK/G6Pase mRNA levels. Cells were treated as in Figure 8. After 24 h of treatment, cell total RNA was extracted for real-time RT-PCR determination of PEPCK/G6Pase mRNA levels, which were normalized to that of GAPDH and plotted as fold of DMSO. Values are mean $\pm \mathrm{SD}$ of 3 separate experiments; ${ }^{*} p<0.05$ and ${ }^{* *} p<0.01$ versus that of DMSO; ${ }^{\$} p<0.05$ versus those of $\mathrm{M}$ alone or $\mathrm{B}$ alone in (b); ${ }^{\# \#} p<0.01$ versus that of $\mathrm{MB}$ salt alone in (c).

demonstrated by our results and other reports $[19,35]$. The attenuation of lipogenesis by $\mathrm{MB}$ salt might also contribute to its suppressing efficacy on hepatic steatosis (Figure 10).

Our results showed that $M$ had no effect on LDLR expression in HepG2 cells and that the LDLR-upregulating activity of MB salt was identical to that of B. Although M was efficacious in lowering serum TG in animal models [4-6] and in a clinical study [7], its activity on cholesterol was controversial. For example, while some reports suggested that $M$ could reduce serum cholesterol and lowdensity lipoprotein cholesterol (LDL-c) levels $[6,36]$, other reports showed that it had no influence on serum or hepatic cholesterol levels $[4,5,7]$. The influence of $M$ on cholesterol metabolism needs further investigation. We infer that $\mathrm{M}$ may have beneficial effects on cholesterol metabolism, but in a LDLR-independent manner.

$\mathrm{M}$ and $\mathrm{B}$ suppressed glucose production and PEPCK/ G6Pase expression through AMPK activation, which suggested that they negatively regulated gluconeogenesis through a common cellular pathway. Accordingly, MB salt suppressed cellular gluconeogenesis more potently than $M$ or B alone.

Unlike that of gluconeogenesis, $\mathrm{M}$ and $\mathrm{B}$ increased basal glucose consumption through different mechanisms (Figure 10). There were evidences indicating that in liver and muscle cells B stimulated basal glucose consumption in an AMPK-independent manner [29] and that it promoted glucose metabolism through induction of glycolysis [29, 34], which might be due to ATP inhibition by this compound [29, $33,34]$. On the contrary, $\mathrm{M}$ enhanced basal glucose consumption in an AMPK-dependent manner in our experiments. $M$ was shown to stimulate glucose metabolism by increasing glucose oxidation and ATP production in muscle cells [9]. In addition, $\mathrm{M}$ might also stimulate the membrane translocation of glucose transporters (GLUTs) [8,37], which could result in an increase of glucose uptake. It should be noted that glucose oxidation and the membrane translocation of GLUTs were able to be modulated by AMPK $[3,38]$. Whether M stimulates these processes through the AMPK pathway needs further investigation. The influence of B on GLUTs was controversial 


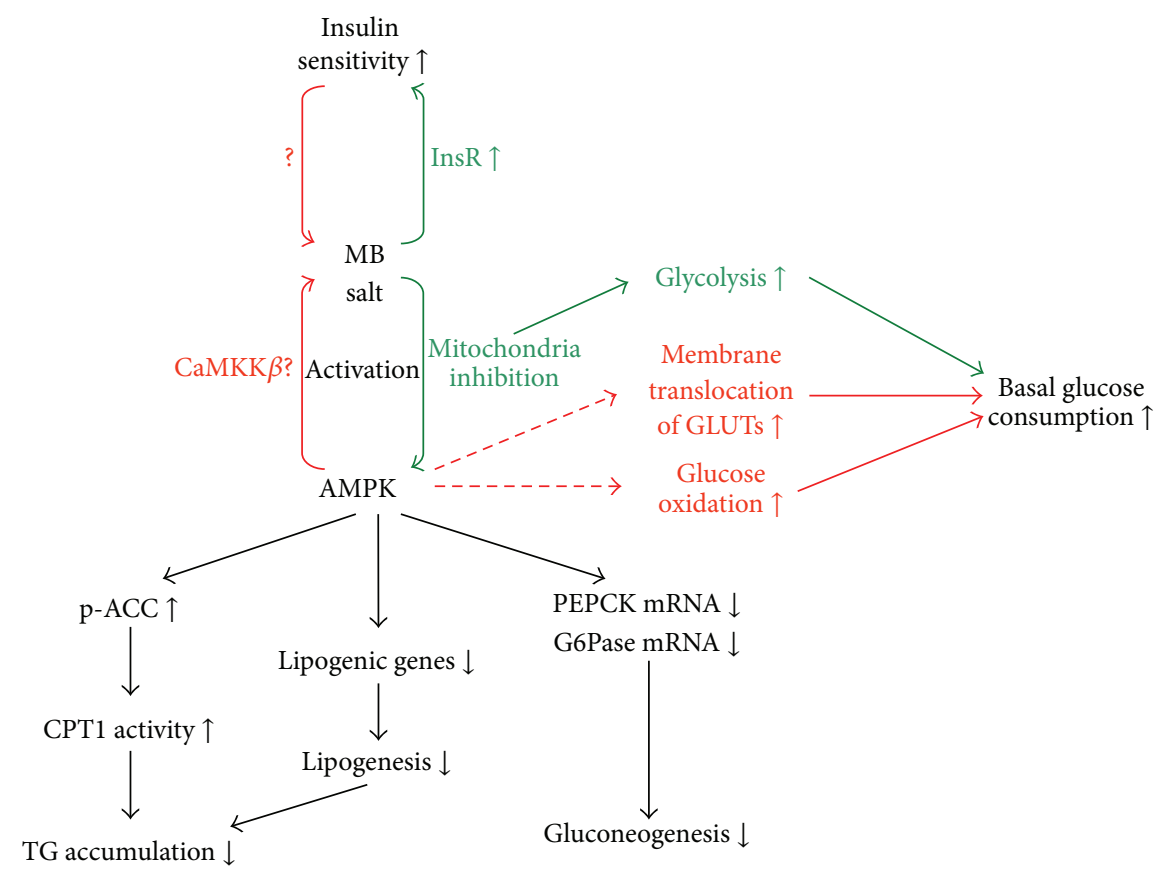

FIGURE 10: A schematic figure summarizes the activities and possible pathways of MB salt in modulating lipid and glucose metabolisms. In HepG2 cells, MB salt could activate AMPK potently, during which M (in red lines) and B (in green lines) might have different modes of actions. AMPK activation could cause the phosphorylation and inhibition of ACC, which in turn stimulated cellular CPT1 activity and suppressed TG accumulation. On the other hand, AMPK activation could result in the downregulation of lipogenic genes, which could reduce intracellular TG as well. PEPCK and G6Pase mRNA expression levels cloud also be downregulated by AMPK activation, which could cause inhibition of gluconeogenesis. M and B might enhance basal glucose consumption through different mechanisms. While B was proved to increase glycolysis and basal glucose consumption in an AMPK-independent manner, the activity of M on basal glucose consumption was AMPK dependent. $M$ was shown to stimulate glucose metabolism by increasing membrane translocation of GLUTs and enhancing glucose oxidation, two processes that were able to be modulated by AMPK. In addition, MB salt could enhance insulin sensitivity potently, although $\mathrm{M}$ and B might act through different mechanisms. Dashed lines and question marks represent pathways and mechanisms that need further investigation and validation.

and some researchers considered that modulation of GLUTs might not be the major mechanism of B to stimulate glucose utilization [21].

Our results proved that all three studying compounds could enhance the insulin-stimulated glucose consumption in HpeG2 cells. When coadministered with insulin, the glucose consumption-stimulating efficacies of $\mathrm{MB}$ salt/M/B were significantly increased. Considering the low concentration of insulin used in our experiment, it could be inferred that $\mathrm{MB}$ salt/M/B revealed insulin-sensitizing effects. The detailed mechanisms of $M$ and $B$ to increase insulin sensitivity are not fully elucidated. Our previous results showed that B could enhance insulin signaling through increasing the expression of insulin receptor (InsR) in liver cells [39]. $M$ had no influence on the Akt pathway $[18,37]$ but was shown to induce CD36 redistribution [13] and activate peroxisome proliferator-activated receptor- $\gamma(\operatorname{PPAR}-\gamma)$ [37] in muscles, which might have beneficial effects on insulin sensitivity. However, the influences of $\mathrm{M}$ on insulin signaling in liver cells need further investigation.

Although $\mathrm{M}$ and $\mathrm{B}$ might promote glucose consumption and stimulate insulin sensitivity through different mechanisms, when they were conjugated in the compound of $\mathrm{MB}$ salt, significantly improved activities were obtained. Together with the results of gluconeogenesis, our findings demonstrated that $\mathrm{MB}$ salt had potent activities in modulating glucose metabolism in HepG2 cells which were superior to that of $\mathrm{M}$ or $\mathrm{B}$ alone.

When $\mathrm{M}$ and $\mathrm{B}$ were administered at the same time to treat HepG2 cells, they stimulated AMPK, reduced intracellular TG, promoted glucose consumption, and suppressed glucose production similar to the $\mathrm{MB}$ salt at an equal molar concentration (data not shown in this study). However, the in vivo situation may be different. When administered alone, $M$ and $B$ are poorly absorbed as single molecules $[40,41]$, which may have unfavourable influences on their pharmacological activities in vivo. However, it was found that $\mathrm{MB}$ salt could be easily dissolved in strong acids [24]. So, in vivo in the stomach, it is possible that MB salt can be fully dissolved in gastric acid. As a single molecule, it is possible that $\mathrm{MB}$ salt may have improved pharmacokinetic parameters as compared to $\mathrm{M}$ and $\mathrm{B}$ when administered together, which deserves further study.

In a previous report [42], $\mathrm{M}$ and B were simply mixed together at a molecular ratio of $1: 1$ and were used to treat diabetic mice. Although the mixture of $\mathrm{M}$ and $\mathrm{B}$ was shown to reduce blood glucose, there was no comparison between the mixture and $\mathrm{M}$ or B alone in that report [42]. Furthermore, 
that composition was proved to be unstable [24, 42], which might limit its potential clinical application. The MB salt is a single molecule; it is stable and can be easily stored [24], which may provide convenience for future clinical application.

$\mathrm{M}$ and $\mathrm{B}$ are natural compounds which belong to different classes and their chemical skeletons are distinct. As a result, they exhibit different toxicities in HepG2 cells and have different mechanisms in modulating metabolisms, as discussed above. As a single molecule, the MB salt contains an M group and a $\mathrm{B}$ group. It can be speculated that the mechanisms and pathways of $\mathrm{MB}$ salt in stimulating lipid and glucose metabolisms may have combined features as compared to those of $\mathrm{M}$ or B alone, as illustrated in Figure 10. Indeed, our results in the present study prove that MB salt stimulates TG metabolism and inhibits glucose production through the AMPK pathway. However, the upstream signals recruited by MB salt to activate AMPK still need further investigation. In addition, the influences of MB salt on glycolysis, glucose oxidation, membrane translocation of GLUTs, and the insulin signaling pathway are not clear; they need detailed investigation and comparison with $\mathrm{M}$ or $\mathrm{B}$ when administered alone.

In conclusion, the new compound of $\mathrm{MB}$ salt has potent activities in stimulating AMPK, reducing intracellular lipid accumulation, enhancing glucose consumption, and suppressing gluconeogenesis in HepG2 cells. Our results may support MB salt as a new kind of agent for the development of novel lipid or glucose-lowering drugs. Future studies should focus on animal experiments to validate the metabolismmodulating activities of $\mathrm{MB}$ salt in vivo.

\section{Competing Interests}

The authors declare no competing interests in this paper.

\section{Acknowledgments}

This work was supported by the National Natural Science Foundation of China (81321004) and National Mega-Project for Innovation Drugs (2014ZX09101005-008).

\section{References}

[1] S. O’Neill and L. O’Driscoll, "Metabolic syndrome: a closer look at the growing epidemic and its associated pathologies," Obesity Reviews, vol. 16, no. 1, pp. 1-12, 2015.

[2] Y. Gao, Y. Zhang, J. Zhu et al., "Recent progress in natural products as DPP-4 inhibitors," Future Medicinal Chemistry, vol. 7, no. 8, pp. 1079-1089, 2015.

[3] W. Chang, L. Chen, and M. Hatch, "Berberine as a therapy for type 2 diabetes and its complications: from mechanism of action to clinical studies," Biochemistry and Cell Biology, vol. 93, no. 5, pp. 479-486, 2015.

[4] F. Guo, C. Huang, X. Liao et al., "Beneficial effects of mangiferin on hyperlipidemia in high-fat-fed hamsters," Molecular Nutrition and Food Research, vol. 55, no. 12, pp. 1809-1818, 2011.

[5] Y. Niu, S. Li, L. Na et al., "Mangiferin decreases plasma free fatty acids through promoting its catabolism in liver by activation of AMPK," PLoS ONE, vol. 7, no. 1, Article ID e30782, 2012.
[6] J. Lim, Z. Liu, P. Apontes et al., "Dual mode action of mangiferin in mouse liver under high fat diet," PLoS ONE, vol. 9, no. 3, Article ID e90137, 2014.

[7] L. Na, Q. Zhang, S. Jiang et al., "Mangiferin supplementation improves serum lipid profiles in overweight patients with hyperlipidemia: a double-blind randomized controlled trial," Scientific Reports, vol. 5, article 10344, 2015.

[8] J. Han, J. Yi, F. Liang et al., "X-3, a mangiferin derivative, stimulates AMP-activated protein kinase and reduces hyperglycemia and obesity in $\mathrm{db} / \mathrm{db}$ mice," Molecular and Cellular Endocrinology, vol. 405, pp. 63-73, 2015.

[9] P. Apontes, Z. Liu, K. Su et al., "Mangiferin stimulates carbohydrate oxidation and protects against metabolic disorders induced by high-fat diets," Diabetes, vol. 63, no. 11, pp. 36263636, 2014

[10] P. S. Sellamuthu, P. Arulselvan, S. Fakurazi, and M. Kandasamy, "Beneficial effects of mangiferin isolated from Salacia chinensis on biochemical and hematological parameters in rats with streptozotocininduced diabetes," Pakistan Journal of Pharmaceutical Sciences, vol. 27, no. 1, pp. 161-167, 2014.

[11] X. Li, X. Cui, X. Sun, X. Li, Q. Zhu, and W. Li, "Mangiferin prevents diabetic nephropathy progression in streptozotocininduced diabetic rats," Phytotherapy Research, vol. 24, no. 6, pp. 893-899, 2010.

[12] T. Miura, H. Ichiki, I. Hashimoto et al., "Antidiabetic activity of a xanthone compound, mangiferin," Phytomedicine, vol. 8, no. 2, pp. 85-87, 2001.

[13] L. Zhou, Y. Pan, R. Chonan et al., "Mitigation of insulin resistance by mangiferin in a rat model of fructose-induced metabolic syndrome is associated with modulation of CD36 redistribution in the skeletal muscle," The Journal of Pharmacology and Experimental Therapeutics, vol. 356, no. 1, pp. 74-84, 2016.

[14] P. B. Pal, K. Sinha, and P. C. Sil, "Mangiferin attenuates diabetic nephropathy by inhibiting oxidative stress mediated signaling cascade, TNF $\alpha$ related and mitochondrial dependent apoptotic pathways in streptozotocin-induced diabetic rats," PLOS ONE, vol. 9, no. 9, Article ID e107220, 2014.

[15] P. S. Sellamuthu, P. Arulselvan, S. Kamalraj, S. Fakurazi, and M. Kandasamy, "Protective nature of mangiferin on oxidative stress and antioxidant status in tissues of streptozotocin-induced diabetic rats," ISRN Pharmacology, vol. 2013, Article ID 750109, 10 pages, 2013.

[16] P. S. Sellamuthu, P. Arulselvan, B. P. Muniappan, S. Fakurazi, and M. Kandasamy, "Mangiferin from salacia chinensis prevents oxidative stress and protects pancreatic $\beta$-cells in streptozotocin-induced diabetic rats," Journal of Medicinal Food, vol. 16, no. 8, pp. 719-727, 2013.

[17] J. Song, J. Li, F. Hou, X. Wang, and B. Liu, "Mangiferin inhibits endoplasmic reticulum stress-associated thioredoxininteracting protein/NLRP3 inflammasome activation with regulation of AMPK in endothelial cells," Metabolism: Clinical and Experimental, vol. 64, no. 3, pp. 428-437, 2015.

[18] F. Wang, J. Yan, Y. Niu et al., "Mangiferin and its aglycone, norathyriol, improve glucose metabolism by activation of AMPactivated protein kinase," Pharmaceutical Biology, vol. 52, no. 1, pp. 68-73, 2014.

[19] G. R. Steinberg and B. E. Kemp, "AMPK in health and disease," Physiological Reviews, vol. 89, no. 3, pp. 1025-1078, 2009.

[20] J. Yao, W. Kong, and J. Jiang, "Learning from berberine: treating chronic diseases through multiple targets," Science China Life Sciences, vol. 58, no. 9, pp. 854-859, 2015. 
[21] J. Yin, J. Ye, and W. Jia, "Effects and mechanisms of berberine in diabetes treatment," Acta Pharmaceutica Sinica B, vol. 2, no. 4, pp. 327-334, 2012.

[22] W. Kong, J. Wei, P. Abidi et al., "Berberine is a novel cholesterollowering drug working through a unique mechanism distinct from statins," Nature Medicine, vol. 10, no. 12, pp. 1344-1351, 2004.

[23] X. Zhang, Y. Zhao, M. Zhang et al., "Structural changes of gut microbiota during berberine-mediated prevention of obesity and insulin resistance in high-fat diet-fed rats," PLOS ONE, vol. 7, no. 8, Article ID e42529, 2012.

[24] H. Teng and W. Wu, "Mangiferin-berberine salt, manufacturing method and use thereof," US Patent 8673864 B2, 2014.

[25] Z. Li, J.-D. Jiang, and W.-J. Kong, "Berberine up-regulates hepatic low-density lipoprotein receptor through Ras-independent but AMP-activated protein kinase-dependent Raf-1 activation," Biological \& Pharmaceutical Bulletin, vol. 37, no. 11, pp. 17661775, 2014.

[26] W. J. Wang, X. N. Luo, X. J. Ma, X. Chao, and Q. Liu, "Cytotoxic effects of eight organic solvents in HepG2 and SMMC7721 human hepatoma cells," Modern Traditional Chinese Medicine, vol. 33, no. 4, pp. 85-86, 2013.

[27] J.-N. Li, D.-Q. Song, Y.-H. Lin et al., "Inhibition of microtubule polymerization by 3-bromopropionylamino benzoylurea (JIMB01), a new cancericidal tubulin ligand," Biochemical Pharmacology, vol. 65, no. 10, pp. 1691-1699, 2003.

[28] Y. Okamoto, S. Tanaka, and Y. Haga, "Enhanced GLUT2 gene expression in an oleic acid-induced in vitro fatty liver model," Hepatology Research, vol. 23, no. 2, pp. 138-144, 2002.

[29] M. Xu, Y. Xiao, J. Yin et al., "Berberine promotes glucose consumption independently of AMP-activated protein kinase activation," PLoS ONE, vol. 9, no. 7, Article ID e103702, 2014.

[30] L.-L. Zhang, L.-N. Ma, D. Yan et al., "Dynamic monitoring of the cytotoxic effects of protoberberine alkaloids from Rhizoma Coptidis on HepG2 cells using the xCELLigence system," Chinese Journal of Natural Medicines, vol. 12, no. 6, pp. 428-435, 2014.

[31] Y.-N. Geng, B. Yu, and W.-J. Kong, "Gastrodin ameliorates oleic acid-induced fat accumulation through activation of AMPK pathway in HL-7702 cells," Chinese Pharmacological Bulletin, vol. 31, no. 1, pp. 39-44, 2015.

[32] L. Qu, B. Yu, Z. Li, W. Jiang, J. Jiang, and W. Kong, "Gastrodin ameliorates oxidative stress and proinflammatory response in nonalcoholic fatty liver disease through the AMPK/Nrf2 pathway," Phytotherapy Research, vol. 30, no. 3, pp. 402-411, 2016.

[33] N. Turner, J.-Y. Li, A. Gosby et al., "Berberine and its more biologically available derivative, dihydroberberine, inhibit mitochondrial respiratory complex I: a mechanism for the action of berberine to activate AMP-activated protein kinase and improve insulin action," Diabetes, vol. 57, no. 5, pp. 1414-1418, 2008.

[34] J. Yin, Z. Gao, D. Liu, Z. Liu, and J. Ye, "Berberine improves glucose metabolism through induction of glycolysis," American Journal of Physiology - Endocrinology and Metabolism, vol. 294, no. 1, pp. E148-E156, 2008.

[35] C.-C. Liao, T.-T. Ou, H.-P. Huang, and C.-J. Wang, "The inhibition of oleic acid induced hepatic lipogenesis and the promotion of lipolysis by caffeic acid via up-regulation of AMPactivated kinase," Journal of the Science of Food and Agriculture, vol. 94, no. 6, pp. 1154-1162, 2014.
[36] S. Muruganandan, K. Srinivasan, S. Gupta, P. K. Gupta, and J. Lal, "Effect of mangiferin on hyperglycemia and atherogenicity in streptozotocin diabetic rats," Journal of Ethnopharmacology, vol. 97, no. 3, pp. 497-501, 2005.

[37] M. D. Girón, N. Sevillano, R. Salto et al., "Salacia oblonga extract increases glucose transporter 4-mediated glucose uptake in L6 rat myotubes: role of mangiferin," Clinical Nutrition, vol. 28, no. 5, pp. 565-574, 2009.

[38] M. R. Fernandez, M. D. Henry, and R. E. Lewis, "Kinase suppressor of Ras 2 (KSR2) regulates tumor cell transformation via AMPK," Molecular and Cellular Biology, vol. 32, no. 18, pp. 3718-3731, 2012.

[39] W.-J. Kong, H. Zhang, D.-Q. Song et al., "Berberine reduces insulin resistance through protein kinase C-dependent upregulation of insulin receptor expression," Metabolism: Clinical and Experimental, vol. 58, no. 1, pp. 109-119, 2009.

[40] H. Ma, H. Chen, L. Sun, L. Tong, and T. Zhang, "Improving permeability and oral absorption of mangiferin by phospholipid complexation," Fitoterapia, vol. 93, pp. 54-61, 2014.

[41] F. Qiu, Z. Zhu, N. Kang, S. Piao, G. Qin, and X. Yao, "Isolation and identification of urinary metabolites of berberine in rats and humans," Drug Metabolism and Disposition, vol. 36, no. 11, pp. 2159-2165, 2008.

[42] X. J. Li, J. G. Deng, Z. L. Tan, N. Liang, and D. Y. Liao, "Experimental study on hypoglycemic effect of the mixture of mangiferin and berberine," Modern Chinese Medicine, vol. 10, no. 12, pp. 26-28, 2008. 

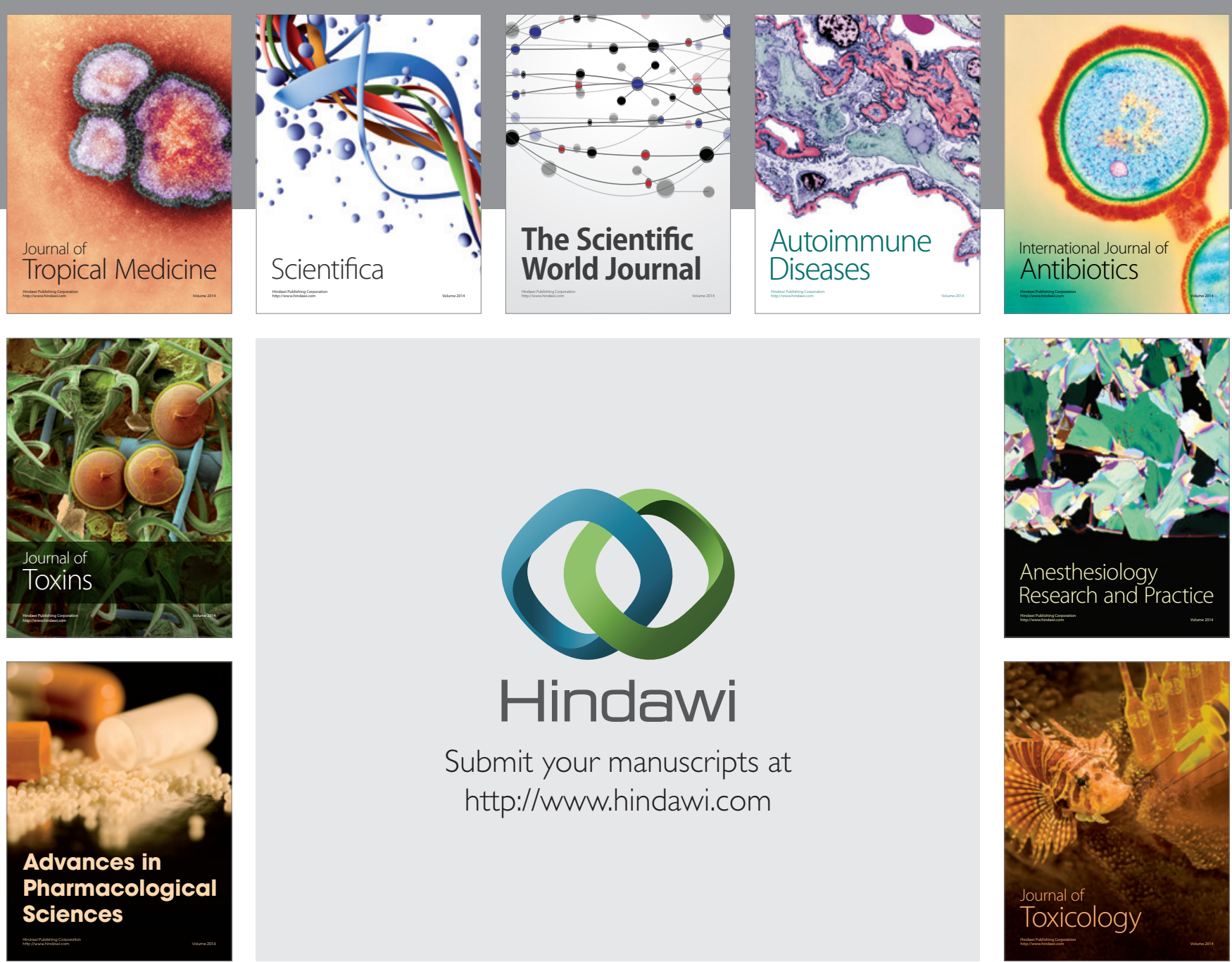

\section{Hindawi}

Submit your manuscripts at

http://www.hindawi.com
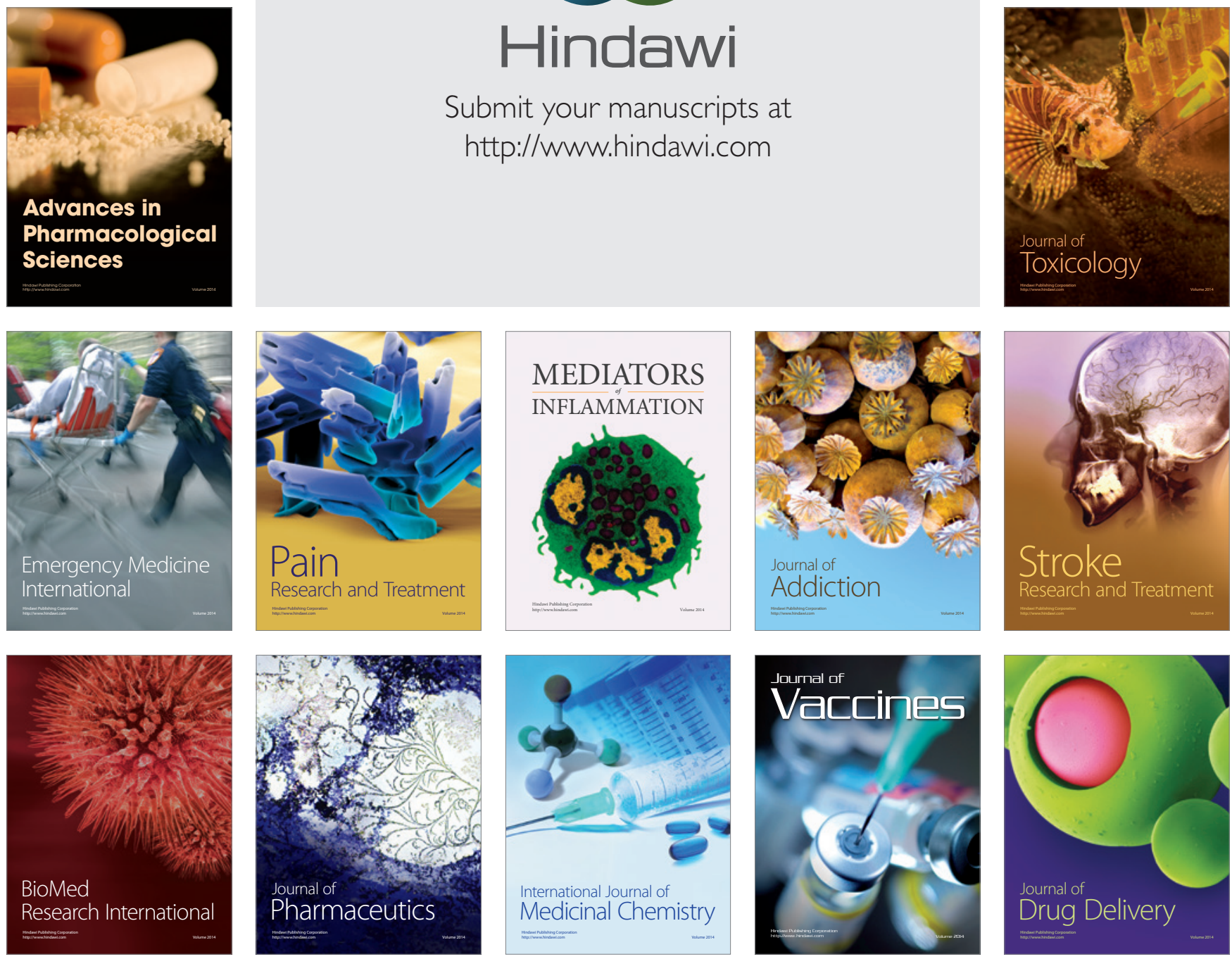